\title{
Loss-in-weight feeding, powder flow and electrostatic evaluation for direct compression hydroxypropyl methylcellulose (HPMC) to support continuous manufacturing
}

\author{
Carl Allenspach ${ }^{\mathrm{a},{ }^{*}}$, Peter Timmins ${ }^{\mathrm{b}, 1}$, Geoffroy Lumay ${ }^{\mathrm{c}}$, James Holman ${ }^{\mathrm{d}}$, Tamara Minko ${ }^{\mathrm{e}}$ \\ ${ }^{\text {a }}$ Bristol-Myers Squibb, 1 Squibb Dr., New Brunswick, NJ 08901, United States \\ ${ }^{\mathrm{b}}$ Bristol-Myers Squibb, Reeds Lane, Moreton Merseyside CH46 1QW, UK \\ c GRASP Laboratory, CESAM Research Unit, University of Liège, Belgium and GranuTools, Awans, Belgium \\ d GEA Group, Technology Management Pharma Solids, Wommelgem, Belgium \\ ${ }^{\mathrm{e}}$ Department of Pharmaceutics, Ernest Mario School of Pharmacy, Rutgers, The State University of New Jersey, 160 Frelinghuysen Road, Piscataway, NJ 08854-8020, \\ United States
}

\section{A R T I C L E I N F O}

\section{Keywords:}

Excipient

Powder flow

Hypromellose

Triboelectric charging

Electrostatics

Screw feeder

Pharmaceutical

\begin{abstract}
A B S T R A C T
Minimizing variability in the feeding process is important for continuous manufacturing since materials are fed individually and can impact the final product. This study demonstrates the importance of measuring powder properties and highlights the need to characterize the feeding performance both offline with multiple refills and in the intended configuration for the continuous manufacturing equipment. The standard grade hydroxypropyl methylcellulose (HPMC) had material buildup on the loss-in-weight feeder barrel from triboelectric charging and resulted in more mass flow excursions and failed refills which were not observed with the direct compression grades. The location of the electrostatic buildup changed when the feeder was connected to a hopper instead of feeding offline into a collection bucket. Overall, the direct compression HPMC exhibited better flow which resulted in more accurate loss-in-weight feeding with less excursions from the target mass flow and all refills were completed in the first attempt. The improvements with the direct compression HPMC would be beneficial when running any continuous process (wet granulation, roller compaction, or direct compression) or other processes where loss-in-weight feeding is utilized, such as melt extrusion or twin screw granulation.
\end{abstract}

\section{Introduction}

There has been significant progress made towards implementing continuous manufacturing for pharmaceutical products in research, equipment, process understanding and modeling to support its implementation. Some of the major benefits of continuous manufacturing include reduced variability, increased monitoring, improved quality, eliminated process scale-up, reduced risk of human errors, smaller physical space requirements, reduced operating costs, increased equipment utilization, improved controls, and potential to utilize modeling for process control or material diversion (Ierapetritou et al., 2016; Schaber et al., 2011). Continuous manufacturing processes have been applied to new compounds as well as switching over from batch processes covering both high and low volume production needs across the currently approved products of Orkambi, Symdeko, Trikafta, Prezista,
Verzenio, Daurismo, and Tramacet. Continuous manufacturing equipment has been designed and integrated to support various processes such as wet granulation, dry granulation, melt extrusion, compression and encapsulation. Some of these systems have been very complicated in design such that different processing modules can be inserted depending on the desired type of manufacturing, while others are designed for a specific process.

Direct compression is one area that has gained increased attention as a result of continuous manufacturing. This resurgence in interest can be attributed to the combination of advantages offered by Continuous Direct Compression (CDC) processes over batch processes, new excipients designed specifically for direct compression, and increased focus within the material science field aimed at API (Active Pharmaceutical Ingredient) modifications and co-processing to improve the physical characteristics of the API and make them more amenable to direct

\footnotetext{
* Corresponding author.

E-mail address: carl.allenspach@bms.com (C. Allenspach).

1 Department of Pharmacy, University of Huddersfield, Huddersfield HD1 3DH, UK.
} 
compression. Historically, direct compression was not seen as being as robust compared to other granulation processes since it can lack processing controls (Leane et al., 2015), has the potential to be more impacted by variability in excipients and API, and prone to issues with segregation and poor flow (Qiu et al., 2016).

Batch processes have had limited success in using direct compression. One of the main challenges is the potential for segregation of the API with the excipients. Due to particle size, shape, density, and other particle property differences between the API and excipients there can be difficulty in achieving a homogeneous mixture with a high propensity for the materials to segregate when flowing/transferring between equipment or during storage. This is one of the reasons that agglomeration or granulation processes such as wet granulation or roller compaction are applied. CDC processes avoid this obstacle by only processing small amounts of material in the system at any given time with minimal transfer distance between the feeders, blenders, and tablet press. CDC processes have even been shown to be viable for low dosage formulations (Van Snick et al., 2017b).

Additional challenges for direct compression are the poor flow and compactability of most APIs and some excipients. Both of these issues can be addressed through particle engineering approaches such as API and excipient coprocessing and excipient modifications for direct compression (Nachaegari and Bansal, 2004; Tomar et al., 2017; Wang et al., 2015). Excipient manufacturers have recognized the necessity and there are now several excipients designed specifically for direct compression processes (Gohel and Jogani, 2005; Rojas et al., 2012; Saha and Shahiwala, 2009).

A key challenge with continuous manufacturing is the need to feed excipients and API accurately using LIW (loss-in-weight) feeders (Engisch and Muzzio, 2015b). Feeding powder consistently and continuously ensures that products are manufactured with reproducible and acceptable critical quality attributes and product quality (Chatterjee, 2012; O'Connor, 2019; Pernenkil and Cooney, 2006; Simonaho et al., 2016). If the feeding rate of one ingredient varies from the set point for even a short period of time, or if there is a spike in material due to accumulation in any part of the system, the resulting variability in concentration could produce out of specification material downstream (Weinekötter and Reh, 1995). Blenders are incorporated in the continuous manufacturing line and can offset some degree of feed variability (Palmer et al., 2020), but when the process shifts from acceptable ranges it results in material rejection via the control system, impacting the overall yield or causing the continuous process to stop for correction. Many studies of LIW feeders have not sufficiently evaluated the impact of feeder refills to the overall feasibility of feeding. This study outlines the powder evaluations and feeder studies necessary to understand the material addition aspect of the continuous process, highlighting the need to execute multiple refill cycles when performing feeding evaluations since the refill process can be impacted with cohesive materials.

Particle triboelectric charging (electrostatics) is a physical effect frequently ignored but can occur with pharmaceutical powders and APIs (Rescaglio et al., 2019; Šupuk et al., 2012; Wong et al., 2015). Factors which influence powder charging can be: type of surface material, contact area, surface roughness, surface cleanliness, chemical structure, absorbed moisture, particle size distribution, shape, roughness, crystallinity and surface area. Even environmental conditions such as contact time, temperature, and relative humidity can influence triboelectric charging (Mukherjee et al., 2016; Naik et al., 2016b; Rescaglio et al., 2019; Wong et al., 2015). Whenever particles are in contact amongst themselves or processing equipment, there is potential for charging to occur. This can happen during many different powder processing and handling operations. Specific situations include shipping in polyethylene bags, weighing with stainless steel or plastic scoops, screening/sieving, pneumatic conveying, mixing, milling, spray drying, and any transfer operations where the powder flows through tubes or out of bins or hoppers (Ceresiat et al., 2019; Ireland, 2010a, b; Kaialy, 2016; Naik et al., 2015; Pingali et al., 2016; Watanabe et al., 2007). During these processes, triboelectric charging of the particles can take place when materials contact each other through friction, sliding or impact and then separate from each other (Bailey, 1984; Matsusaka et al., 2010). The time for these charges to dissipate, especially at large scale, has not been well studied and some materials like magnesium stearate continue to hold the charge even after grounding (Carter et al., 1998; DesRosiers Lachiver et al., 2006; Peart, 2001).

Triboelectric charging can have positive effects such as enhancing API blend uniformity via adhesion to larger carrier particles (Mäki et al., 2007; Naik et al., 2016c; Staniforth and Rees, 1982; Staniforth and Rees, 1981) but it can also disrupt pharmaceutical processes. It can impact agglomeration and the potential for jamming and segregation (Andreou et al., 2009; Beeckmans et al., 1979; Hao et al., 2013; Naik et al., 2015; Pu et al., 2009), punch sticking on tableting (Samiei et al., 2017), die filling/ weight uniformity during tableting (Nwose et al., 2012), and even general powder adhesion onto many surfaces. Adhesion issues due to electrostatics is often addressed in analytical testing (wet chemistry) but can also be very problematic for PAT applications relying on sensor surfaces that can become fouled if particles adhere to the window of the sensor. The triboelectric charging of some HPMC materials have been evaluated (Ghori et al., 2015; Ghori et al., 2014) but the DC (Direct Compression) grades and the impact to LIW feeding have not been investigated previously.

Powder flow can impact the continuous blending of materials in various continuous mixing systems (Harwood et al., 1975; Van Snick et al., 2017a) and the most difficult aspect of continuous mixing is the feeding of materials (Williams, 1976). This study will evaluate the impact of powder flow and electrostatic charge on LIW feeding systems which utilize feedback control by assessing feed rate accuracy and hopper refills. It will also demonstrate the importance of testing with multiple refills and awareness of potential differences when incorporating the feeders into the full continuous manufacturing system.

\section{Materials and methods}

\subsection{Materials}

Six different Benecel ${ }^{\mathrm{TM}}$ Hypromellose lots (Ashland Inc. Wilmington, DE) consisting of three standard CR grades of HPMC K100M, K15M, K4M and three new DC (Direct Compression) grades of HPMC K100M, K15M, K4M. Material properties for the six materials are provided in Table 1 . These materials were previously characterized in earlier studies (Allenspach et al., 2020). The standard grades are referred to as controlled release (CR) grades by the manufacturer as they were the first

Table 1

Benecel $^{\mathrm{TM}}$ Hypromellose lots and properties used in this study. Data provided by Ashland, Inc.

\begin{tabular}{|c|c|c|c|}
\hline HPMC Material Grade & Abbreviated as & Weight Average Molecular Weight & Nominal Viscosity of $2 \%$ solution $(\mathrm{mPa} * \mathrm{~S})$ \\
\hline Benecel K100M PH CR & K100M CR & $1,000,000$ & $75,000-140,000$ \\
\hline Benecel K15M PH CR & K15M CR & 575,000 & $13,500-25,200$ \\
\hline Benecel K4M PH CR & K4M CR & 400,000 & $2,700-5,040$ \\
\hline Benecel K100M PH DC & K100M DC & $1,000,000$ & $75,000-140,000$ \\
\hline Benecel K15M PH DC & K15M DC & 575,000 & $13,500-25,200$ \\
\hline Benecel K4M PH DC & K4M DC & 400,000 & $2,700-5,040$ \\
\hline
\end{tabular}


improvements to HPMC for use as an excipient. The ' $\mathrm{K}$ ' defines it as a Hypromellose 2208 type, which indicates a specific range of ratios of hydroxypropyl and methoxy group substitutions. This ratio determines the overall performance of the HPMC in hydrophilic matrix systems. Kchemistry HPMC has the highest ratio of hydroxypropyl to methoxy substitution allowing for fast gel barrier formation beneficial for controlled release tablets. The fast rate of hydration followed by quick gelation is required for the polymer to form a protective gelatinous layer around the matrix to modulate the release of the drug. This evolving gel layer develops into the tablet over time to control drug release, preventing the tablet from immediately disintegrating and is especially critical with water-soluble drugs and water-soluble excipients (The Dow Chemical Company, 2006; Timmins and Allenspach, 2018; Timmins et al., 2014). The ' $M$ ' indicates viscosity $x 1000$ (e.g. $K 100 M=$ viscosity of $100,000 \mathrm{mPa} * \mathrm{~S}$ ). These grades represent a range of viscosities commonly employed for controlled released hydrophilic matrix tablets and are currently the only grades available as DC types. The DC grades are co-processed with silica at $<1 \% \mathrm{w} / \mathrm{w}$ to improve flow and compactability, which results in better performance than direct blends of HPMC with silica (Tewari et al., 2019).

\subsection{Powder flow characterization}

These materials were previously characterized for many different particle properties (Allenspach et al., 2020) such as size, morphology and especially for powder flow, which can be difficult to evaluate as flow dynamics can change under different conditions (Lumay et al., 2012). This work utilized different testing methodologies such as static angle of repose, automated powder flow in a drum across different speeds, and tapped density measurements after each tap to characterize the powder flow. The powder electrostatics were also explored for the first time for the DC HPMC materials which was found to impact the feeder studies.

\subsection{Static angle of repose}

The angle of repose is a common method to evaluate granular materials with varying techniques for estimation and measurement (Beakawi Al-Hashemi and Baghabra Al-Amoudi, 2018). The challenge with cohesive powders is that they form irregular heaps which makes it particularly difficult to measure the angle of repose accurately compared to non-cohesive powders that form well defined heaps with consistent angles on all sides (Boschini et al., 2015). The angle of repose test can be very sensitive to the method and handling used to create the heap. For this reason, the GranuHeap instrument (Granutools, Awans, Belgium) was used to measure the angle of repose of the cohesive HPMC. The instrument consists of an automated method to create the heap along with multi-angle image analysis. Calibration consisted of measuring a $45^{\circ}$ calibration piece. Then the initialization tube was filled with $100 \mathrm{ml}$ of powder and the measurement started. The initialization tube has an internal diameter equal to the support plate and lifts slowly at a speed of $5 \mathrm{~mm} / \mathrm{s}$. The powder flows from the initialization tube to form a heap on the cylindrical test plate and the system uses a CCD camera to capture 16 images during a slow, controlled rotation of the test plate to view different heap orientations so that any asymmetric heap shapes are recorded. The test was performed in triplicate for each material. After each test the equipment was cleaned, and a fresh sample was used for each test. The software was used to perform image analysis of the air-powder interface and provided the angle of repose for each image which is quantified as the angle of an isosceles triangle with the same surface area of the actual heap. Generally, the lower the angle of repose the better flowing the materials. The heap height is the height of the powder heap which is typically higher for more cohesive materials. The static cohesion index is derived from the difference between the measured heap interface and an ideal isosceles triangle. Non-cohesive powders will have a static cohesion index close to zero and as the heap shape deviates more from an isosceles triangle with cohesive powders, the static cohesion index increases (Boschini et al., 2015). All tests were performed with room conditions between $23.6-25.1{ }^{\circ} \mathrm{C}$ and $34.1-47.2 \%$ relative humidity. The tests were alternated between samples of CR and DC to reduce any bias from environmental conditions.

\subsection{Flow angle and cohesive index}

The GranuDrum (Granutools, Awans, Belgium) was used for powder flow in a drum in order to determine the dynamic angle of repose for the materials. The equipment has a transparent $84 \mathrm{~mm}$ diameter drum that is filled with $50-55 \mathrm{ml}$ of powder such that the drum was approximately half full. The drum was sealed and rotated at different speeds. The rotating drum was backlit and utilized a CCD camera to capture images of the powder flowing at speeds of 2-20 rpm (every $2 \mathrm{rpm}$ ) and then 20-60 rpm (every $5 \mathrm{rpm}$ ). Varying the speed of rotation allowed for more in-depth evaluation of powder flow to evaluate shear thinning or shear thickening behavior. The powder was conditioned for $15 \mathrm{~s}$ and then images were taken every second such that 40 images were acquired at each of the 18 speeds. The software detected the interface of the powder/air and determined average angle and standard deviations for each velocity. The flowing angle was determined from the average angle measured at the center of the powder/air interface. The cohesive index is related to the powder cohesion and is evaluated from the temporal fluctuations of the powder/air interface. A non-cohesive, excellent flowing powder would have very low fluctuations and hence cohesive index close to zero while a highly cohesive powder would have more variability of the flow and a higher cohesive index. Each test was repeated using new samples and alternating between CR and DC materials to reduce testing bias. All measurements were made between 22.7-25.5 ${ }^{\circ} \mathrm{C}$ and $40-49 \% \mathrm{RH}$.

\subsection{Tapped density}

The automated GranuPack (Granutoools, Awans, Belgium) removes much of the inaccuracy with traditional tapped density tests where the measurements are estimated by eye using a graduated cylinder. The interpretation of the result with traditional testing is especially difficult for the initial measurement since the powder surface is very erratic after pouring powder into the graduated cylinder. The GranuPack instrument also provides more information around the progression of the density change over time by taking a distance measurement after every tap and not just the final value. The test method consisted of adding approximately $11 \mathrm{~g}$ of sample into a grounded metallic initialization tube. Then the initialization tube was lifted at a slow speed of $1 \mathrm{~mm} / \mathrm{s}$ such that the powder fell gently into a slightly larger ( $26 \mathrm{~mm}$ diameter) measurement tube to standardize the sample loading. A lightweight aluminum platen was then gently placed on the top of the powder with the help of a placement string. The measurement tube was lifted $1 \mathrm{~mm}$ and dropped, followed by an automatic measurement of the height which was repeated 1,500 times. Utilizing this methodology the evolution of the tapped density at each tap could be measured such that materials with similar bulk and final tap density might show differences in the settling of particles and the progression of the tapped density. Each measurement was repeated a second time with new material after cleaning the test cell. All tests were performed with room conditions between 22.9-25.3 ${ }^{\circ} \mathrm{C}$ and $39.3-47.3 \%$ relative humidity. The equipment automatically calculated the initial density, final tapped density, number of taps to get to half the final density ( $\left.\mathrm{n}^{1 / 2}\right)$, Hausner ratio (final tapped density divided by initial density), and the extrapolated maximum density from tapping $(\rho[\infty])$.

\subsection{Electrostatic charge density / triboelectric charging}

Triboelectric charging of the powders was determined using a GranuCharge Instrument (GranuTools, Awans, Belgium). The equipment consists of a $700 \mathrm{~mm}$ long, $47 \mathrm{~mm}$ diameter V-shaped tube made of 
316 L stainless steel where the powders acquire a charge when flowing through the tube. The V-tube geometry combines the different mechanisms leading to tribo-electrification: (i) friction between the grains, (ii) friction between the grains and the wall, and (iii) impact of the grains on the wall at the connection between the two tubes where the powder changes direction (Rescaglio et al., 2019). Approximately $50 \mathrm{ml}$ of the powder was weighed in a glass beaker and grounded to dissipate any charge. The powder was then poured directly into the Faraday cup to determine the initial charge. The Faraday cup was then cleaned and replaced. A new sample of $50 \mathrm{ml}$ of powder was weighed, grounded and then fed into the testing tube using a vibratory feeder set at $25 \%$ vibration. The feeder and tubes were grounded before the measurement to replicate the grounding of processing equipment used in pharmaceutical manufacturing. After flowing through the testing tubes, the powder was collected into a Faraday cup and the final charge was measured. The measurements were repeated five times for each material. Charge density $(\mathrm{nC} / \mathrm{g}$ ) was then calculated by dividing the net charge by the mass of the material for the initial and final charges and the accumulated charge was determined as the difference.

All tests were performed between $23-26{ }^{\circ} \mathrm{C}$ and $39-47 \% \mathrm{RH}$, alternating between $\mathrm{CR}$ and $\mathrm{DC}$ types to reduce any environmental bias. It has been demonstrated that powders have a material specific threshold to relative humidity, above which they show significant changes in the triboelectric charging (Schella et al., 2017). The GranuCharge equipment has the capability to test different humidification levels with the additional environmental attachment, but this aspect was not evaluated.

Additional testing was performed with HPMC K100M CR using tubes with different materials of construction commonly found in pharmaceutical manufacturing environments (316L Stainless Steel, PolyEthylene, Poly-Vinyl Chloride, Aluminum, and High Density PolyEthylene) to determine the charging effect with different contact materials using the same testing method as described. Single measurements were made for each material.

\subsection{Compact feeder equipment}

The GEA loss-in-weight compact feeder (GEA, Columbia, Maryland) was used for this study. This equipment is identical to the GEA Compact Feeders (CF) utilized in the GEA CDC-50 equipment designed for continuous direct compression and shown in Fig. 1.

The GEA Compact Feeder uses a twin screw conveying system for powders with three different gear servos available depending on the targeted feed rate. There is also a horizontal impeller above the screws to prevent cohesive materials from bridging in the hopper, ensuring

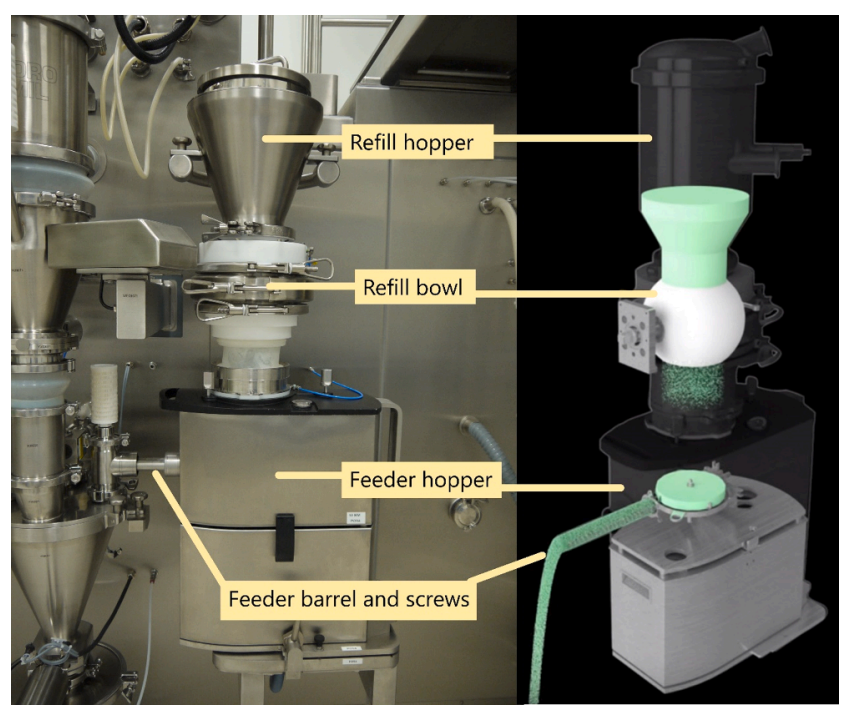

Fig. 1. LIW feeder system. Diagram of GEA Compact Feeder module. complete filling of the screws. The impeller rotates counterclockwise making one turn for every 8 turns of the screw. During normal operation, the feeder uses gravimetric control where the load cell determines the mass flow, which is compared to the target value. The screw speed is then adjusted to keep the actual mass flow as close to the target as possible. When the LIW feeder goes into volumetric mode it is the most susceptible to feeding errors because there is no feedback loop to keep the mass flow on target. The feeder will go into volumetric mode during a refill or when a perturbation occurs, such as scale disturbance, vibration on scales, or when there is feeding difficulty.

During a refill event it is necessary for the feeder to switch from a gravimetric feed rate (mass per time) to a volumetric (fixed speed based on feed factor array and the mass of material) because additional mass is added to the feeders. The refill is triggered when the feeder reaches a defined minimum mass setpoint (approximately $160 \mathrm{~g}$ was used for HPMC) at which point the feeder switches to volumetric feeding and the refill hopper rotates 180 degrees to dump additional powder into the hopper which typically takes $0.6-1.2 \mathrm{~s}$. While the system uses gravity to empty the hopper there is vibration and the top up system is designed to come to a sudden stop once turned 180 degrees, causing a knock that assists in emptying the material. The feeder continues in volumetric mode to stabilize before switching back to gravimetric mode. In order to improve the accuracy during volumetric feeding, the system utilizes a feed factor array based on bins of different powder mass. The feed factor array is set using a calibration run and updated constantly during the run based on measured data. This ensures consistent mass flow during a refill and determines what screw speed should be used when exiting volumetric mode. The feed factor itself is a measure of the mass per revolution and is a factor of the total mass or head pressure from the material in the hopper. The higher the head pressure the more material is fed by the screws per revolution, and the higher the feed factor.

In order to evaluate the impact of refills for this study, material was fed such that the hopper was refilled at least three times for each material using the $1.2 \mathrm{~L}$ refill bowl. The refill bowl is available in $0.4,0.8$, 1.2 or $1.6 \mathrm{~L}$ sizes allowing for optimization of the refill. In some cases it is beneficial to provide for more frequent refills with less material (Berthiaux et al., 2008; Engisch and Muzzio, 2015a). This provides for less variability in the head pressure and potentially more consistent feeding but also increases the frequency of refills and overall amount of time where the system is not running gravimetrically. For materials with poor flow and a tendency to rathole or bridge in the hopper or refill bowl it may be beneficial to use larger bowls, as the smaller bowls have smaller openings which could be more prone to bridging or clogging.

The screw feeder has different sized outlet screens that can be placed at the end of the screws to facilitate more consistent feeding. The size of meshes available are either $8 \mathrm{~mm}$ (open), $2 \mathrm{~mm}$ (coarse) or $1 \mathrm{~mm}$ (fine). Material is pressed between holes in the screen so that cohesive powders will fall off more reproducibly and it can also help with free-flowing powders to create some back pressure and moderate the flow. In some instances, the powders can be dosed with improved accuracy using a screen, but it is highly material dependent. For the HPMC materials even the large coarse screen created significant back pressure in the system which caused the screws to over torque and stop. As a result, no outlet screen was used in these studies.

The importance of establishing the Residence Time Distribution (RTD) for continuous systems has been highlighted by many authors (Bhaskar and Singh, 2019; Escotet Espinoza, 2018; Gao et al., 2011; Karttunen et al., 2019; Pernenkil and Cooney, 2006; Vanarase et al., 2013). The RTD of the GEA Compact Feeder has been evaluated and shown to have good results (short RTD) compared to other loss-inweight feeders (Van Snick et al., 2019). This is beneficial as it reduces the time for an excursion to pass through the system and results in less rejection of material. Determining the residence time for the materials in the entire continuous system will support determining an acceptable level of variation in the feed rate for each of the materials. 


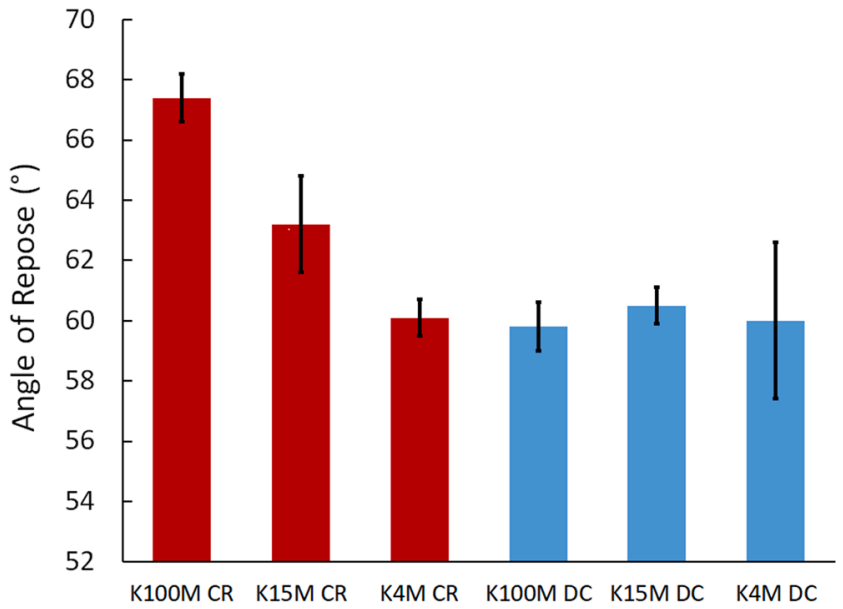


Table 4

Bulk and tapped density measurements from GranuPack. Mean and (standard deviation) shown.

\begin{tabular}{|c|c|c|c|c|c|}
\hline HPMC Grade & Bulk Density $(\mathrm{g} / \mathrm{ml})$ & Tapped Density (g/ml) & $\mathrm{n}^{1 / 2}$ (taps) & Hausner ratio & $\rho[\infty](\mathrm{g} / \mathrm{ml})$ \\
\hline K100M CR & $0.288(0.003)$ & $0.411(0.004)$ & $83(9)$ & $1.426(0.001)$ & $0.463(0.006)$ \\
\hline K15M CR & $0.312(0.001)$ & $0.431(0.002)$ & $82(9)$ & $1.384(0.001)$ & $0.482(0.001)$ \\
\hline K4M CR & $0.324(0.001)$ & $0.450(0.000)$ & $89(16)$ & $1.387(0.006)$ & $0.510(0.006)$ \\
\hline K100M DC & $0.344(0.004)$ & $0.477(0.006)$ & 75 (17) & $1.387(0.037)$ & $0.533(0.011)$ \\
\hline K15M DC & $0.324(0.004)$ & $0.467(0.004)$ & $117(16)$ & $1.442(0.003)$ & $0.533(0.008)$ \\
\hline K4M DC & $0.335(0.000)$ & $0.469(0.004)$ & $113(16)$ & $1.401(0.011)$ & $0.533(0.001)$ \\
\hline$P$ value (CR vs $D C)^{*}$ & 0.011 & 0.002 & 0.156 & 0.494 & 0.003 \\
\hline
\end{tabular}

* Items in bold where $\mathrm{P}$ value $<0.05$.

angle and the average cohesive index against the drum speed.

The average flow angle shown in Fig. 4 increased for both materials from a drum speed of $2 \mathrm{rpm}$ and reached a maximum at $8 \mathrm{rpm}$ for DC and $10 \mathrm{rpm}$ for CR and then decreased for both. Overall, the flow angle was slightly lower for the DC materials at drum rotation speeds $>10 \mathrm{rpm}$ indicating less cohesive material, but the variability was high with overlapping standard deviations between the types.

The average cohesive index, which is a measure of the variability of the flow, increased for both materials when the drum speed increased from 2 to $20 \mathrm{rpm}$ although the DC type had a lower cohesive index across these speeds compared to the CR type as shown in Fig. 5. As the rotation speed increased further, the cohesive index leveled out for the CR type but the DC materials showed a more regular and then better flow. This shear thinning behavior could be explained by a powder aeration at higher speeds. A similar decrease in cohesive index and shear thinning at increasing speeds was observed for lactose blended with $2 \%$ Mesoporous silica before testing (Lumay et al., 2019).

\subsection{Triboelectric charging of HPMC}

Very few studies have assessed the importance of electrostatics during LIW feeding of powders and the potential impact it can have on the feeding process even when that possibility is acknowledged as a potential source of feeding error (Engisch and Muzzio, 2012). Triboelectric charging can cause the powder to adhere to the LIW feeder barrel at the output and create electrostatic buildup of the powder. Over time, as the buildup increases it can become dislodged causing small or large spikes of powder to be added. When this occurs, it is detected by the control system since the mass of the equipment including the screw barrel is being measured to calculate the flow rate when in gravimetric control mode. However, when the LIW feeder was connected to the full

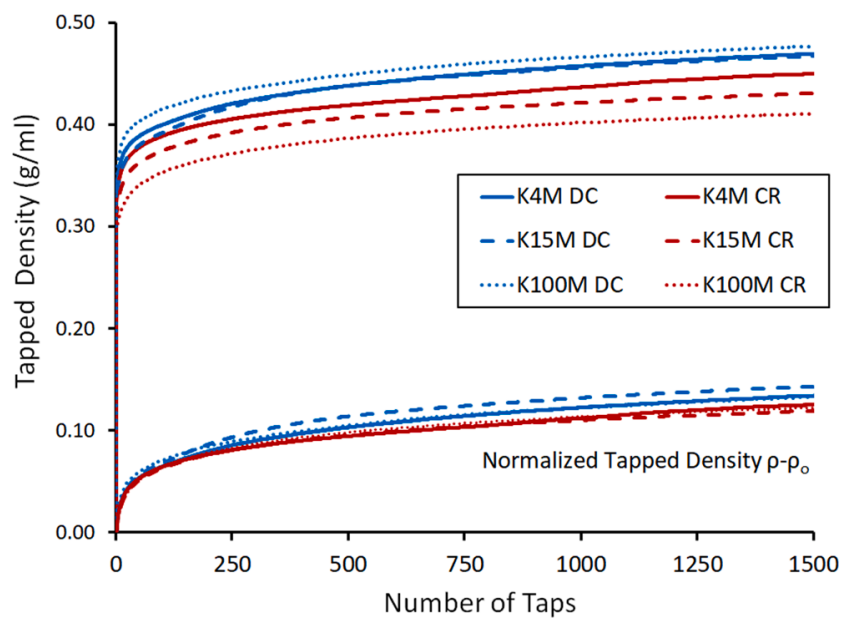

Fig. 3. Tapped density profiles from the GranuPack. CR in red and DC in blue. K4M solid line, K15M dashed line, and K100M dotted line. Curves for tapped density normalized by subtracting the initial density are at the bottom.
CDC-50 hopper system which feeds into the blender, the buildup no longer occurred on the LIW feeder. Instead, the material started to build up on the discharge opening of the hopper. Since the hopper is not connected to the LIW feeder, any resulting material spikes would be invisible to the control system and could be problematic to product quality unless the blender was capable of blending out the unmeasured spike of material.

Of the materials studied, the CR types all had a small positive initial charge with significant charge accumulation after testing with 316 Stainless Steel. The accumulation of material on the barrel of the LIW feeder took on a different aspect depending on the feed rate as shown in

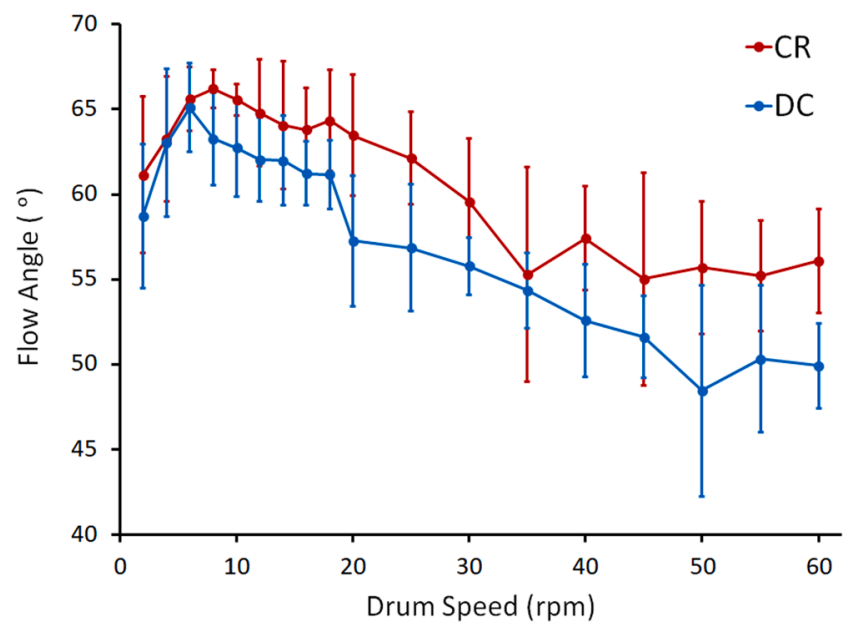

Fig. 4. Average flow angle at each drum rotation speed measured on GranuDrum. CR in red and DC in blue. Mean \pm standard deviation shown.

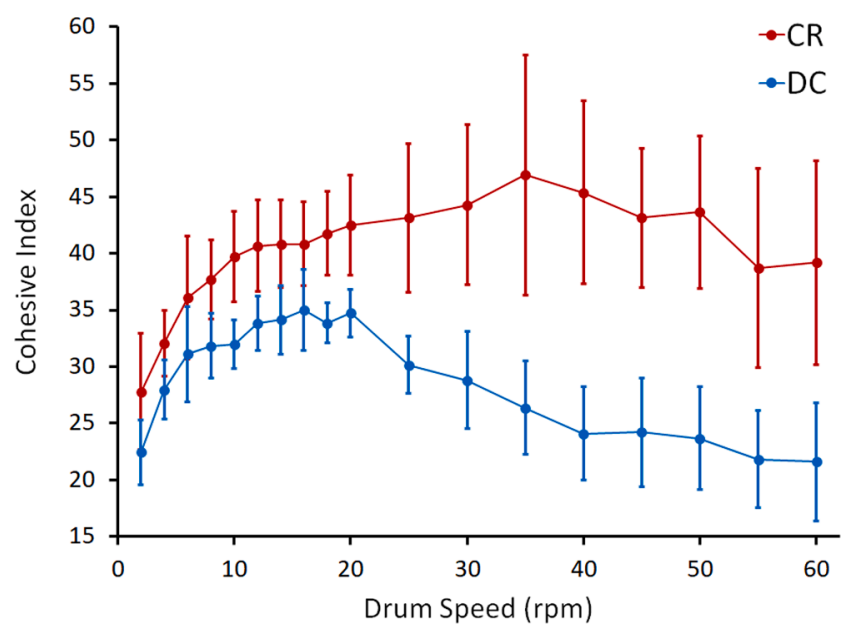

Fig. 5. Average cohesive index at each drum rotation speed measured by GranuDrum. CR in red and DC in blue. Mean \pm standard deviation shown. 
a)

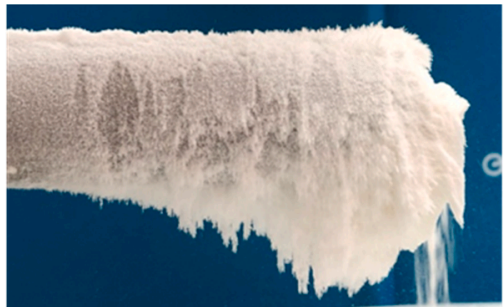

b)

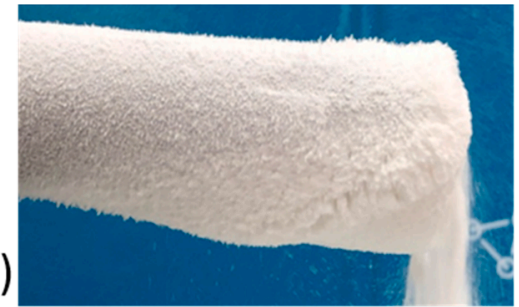

c)

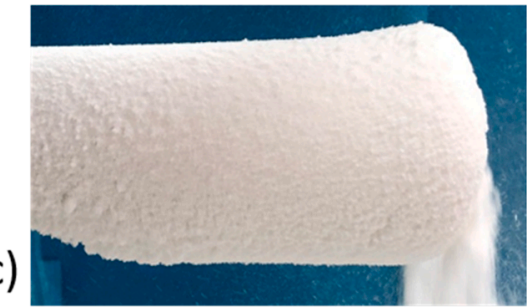

Fig. 6. Examples of electrostatic powder buildup of HPMC K4M CR at feed rates of a) $1 \mathrm{~kg} / \mathrm{h} \mathrm{b}) 7.5 \mathrm{~kg} / \mathrm{h} \mathrm{and} \mathrm{c)} 15 \mathrm{~kg} / \mathrm{h}$.

Fig. 6. Only K100M CR had a positive charge after testing with all other materials having a negative charge and the HPMC CR grades had charge accumulation such that $\mathrm{K} 100 \mathrm{M}>\mathrm{K} 15 \mathrm{M}>\mathrm{K} 4 \mathrm{M}$. This did not show the same trend as seen in another study where the magnitude of charge and surface adhesion inside a container decreased with increased polymer chain length such that $\mathrm{K} 4 \mathrm{M}>\mathrm{K} 15 \mathrm{M}>\mathrm{K} 100 \mathrm{M}$ ranging from 12.3 to 3.9 $\mathrm{nC} / \mathrm{g}$ depending on the HPMC grade and particle size (Ghori et al., 2014). These opposing results may have come from the alternate test method of shaking powder in a stainless-steel container or from the HPMC itself which was from a different supplier and had different morphology.

The DC types all started with a small negative charge initially and only had a slight charge accumulation after testing. This correlated with a comparatively small amount of material accumulation on the LIW feeder barrel as shown in Fig. 7 and Table 5. The DC grades have been co-processed using a small amount of silicon dioxide which may provide both a mitigation against triboelectric charging as well as a flow aid. Similarly, mesoporous silica was studied in combination with lactose, starch and microcrystalline cellulose and was shown to decrease the charging of those materials (Lumay et al., 2019). This is surprising since colloidal silicon dioxide on its own was shown to have the most negative chargeability of the materials studied and had the most electrostatic accumulation (Ramirez-Dorronsoro et al., 2006).

It is important to note that when there is buildup of material on the LIW feeder barrel there is the potential for some of this material to fall off in clumps causing spikes. This was observed during the feeder trials and resulted in measureable feeding spikes with the $\mathrm{CR}$ grade. An example of this is shown in Fig. $8 \mathrm{a}$ and $\mathrm{b}$ and has been seen with some other materials (Engisch and Muzzio, 2015b).

A majority of LIW feeder studies consist of feeding materials offline into collection containers, as was performed in this study. However, when LIW feeders are implemented in a continuous process there are multiple feeders inserted into a small hopper which feed a continuous blender. When the hopper was added to the LIW feeder there was no material accumulation on the feeder barrel, but it did accumulate at the output of the hopper instead as shown in Fig. 8c and d. This is a critical finding because if the material were to build up anywhere else in the equipment other than the feeder barrel it would not be apparent to the control system during gravimetric feeding and would go unnoticed by the control system. It is possible that other materials in the formulation being fed into the same hopper could mitigate this electrostatic nature depending on their charge and as a result, the entire formulation and processing system should be considered.

This study also explored the effect of materials of construction commonly used in pharmaceutical manufacturing using only K100M CR grade of HPMC. Charge accumulation was in the order of 316L Stainless Steel $>$ Poly-Ethylene $>$ Poly-Vinyl Chloride $>$ Aluminum $>$ High Density Poly-Ethylene, with approximately a factor of 2 between the high and low as shown in Fig. 9. Previous studies have also demonstrated that the contact material can impact the charge accumulation of powders for Ibuprofen, theophylline, lactose monohydrate and microcrystalline cellulose using a V-Blender constructed of some common
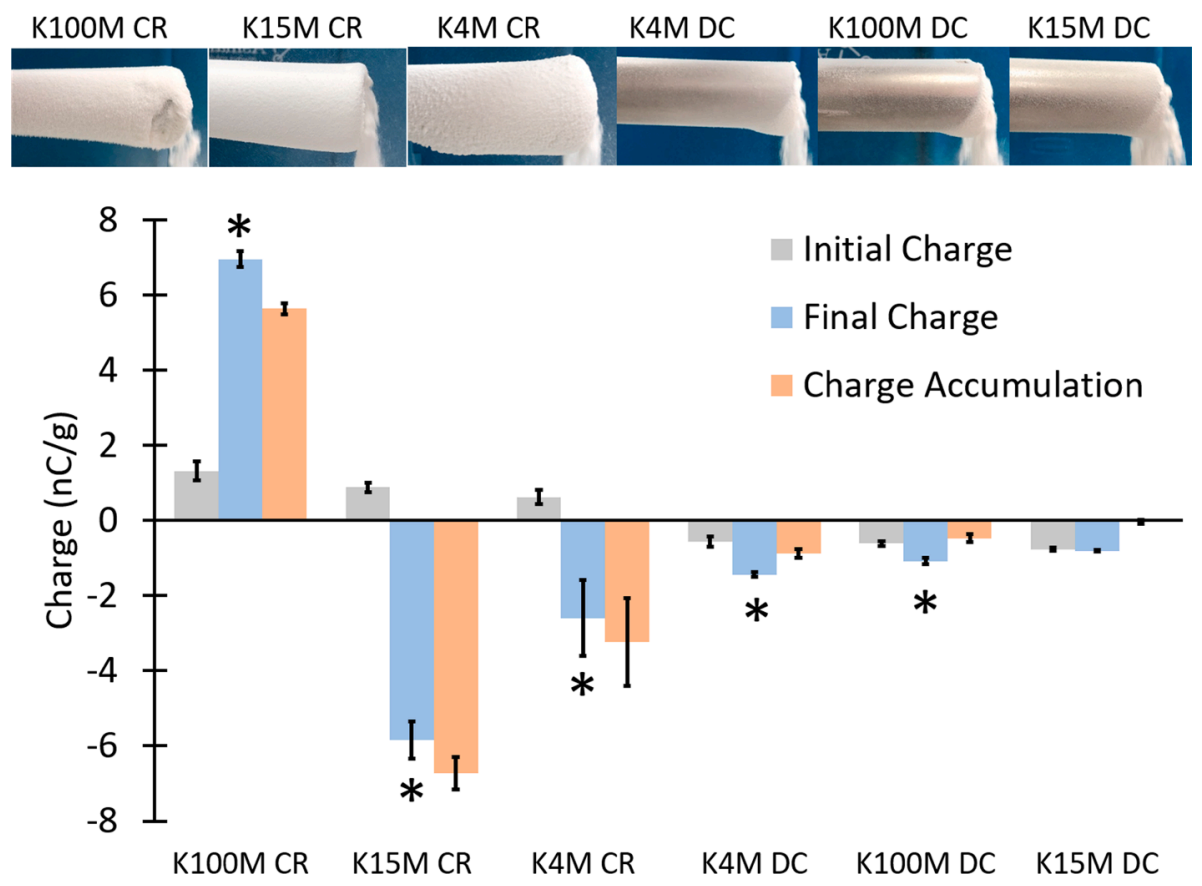

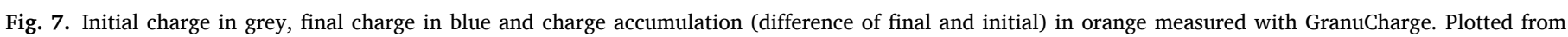

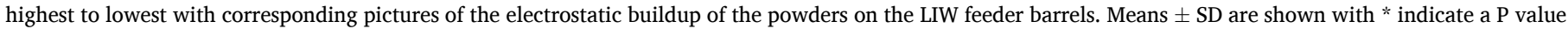
$<0.05$ for initial vs final charge. 
Table 5

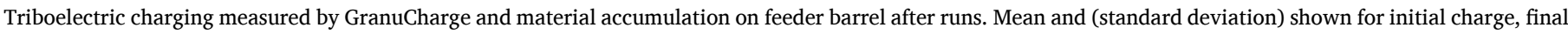
charge and charge accumulation.

\begin{tabular}{|c|c|c|c|c|c|c|}
\hline \multirow[b]{2}{*}{ HPMC Grade } & \multirow[b]{2}{*}{ Initial Charge q0 (nC/g) } & \multirow[b]{2}{*}{ Final Charge qf (nC/g) } & \multirow[b]{2}{*}{ Charge Accumulation $\Delta \mathrm{q}(\mathrm{nC} / \mathrm{g})$} & \multicolumn{3}{|c|}{ Material accumulation on feeder barrel ( $g$ ) } \\
\hline & & & & $1 \mathrm{~kg} / \mathrm{h}$ & $7.5 \mathrm{~kg} / \mathrm{h}$ & $15 \mathrm{~kg} / \mathrm{h}$ \\
\hline K100M PH CR & $1.32(0.25)$ & $6.96(0.22)$ & $5.64(0.15)$ & 0.81 & 5.13 & 6.52 \\
\hline K15M PH CR & $0.88(0.13)$ & $-5.84(0.49)$ & $-6.73(0.43)$ & 0.36 & * & * \\
\hline K4M PH CR & $0.63(0.19)$ & $-2.60(1.01)$ & $-3.23(1.17)$ & 4.05 & * & 13.53 \\
\hline K100M PH DC & $-0.61(0.05)$ & $-1.08(0.09)$ & $-0.47(0.10)$ & 0.05 & 0.14 & 0.21 \\
\hline K15M PH DC & $-0.76(0.04)$ & $-0.80(0.02)$ & $-0.04(0.05)$ & 0.28 & 0.10 & 0.19 \\
\hline K4M PH DC & $-0.56(0.14)$ & $-1.44(0.07)$ & $-0.88(0.12)$ & 0.35 & 0.31 & 0.15 \\
\hline$P$ value (CR vs DC) & $<0.001$ & $<0.001^{\text {क. }}$ & $<0.001^{* * \hbar}$ & - & - & - \\
\hline
\end{tabular}

* Data not collected. Electrostatic differences were not known at the time of performing feeding trials.

** The absolute value was used for statistical significance, due to positive final charge of K100M CR.

materials (Naik et al., 2016a).

\subsection{LIW feeder studies}

The data was not evaluated when the feeder was running in volumetric mode (during the refill cycle) as the weights are inaccurate when the refill hopper engages for the refill. A catch scale to weigh the material being fed from the LIW feeder is one way to accurately capture the feed rate during volumetric mode but was not available for these experiments.

The first $20 \mathrm{~s}$ for refill 1 (the start of feeding) was removed for all of the trials for 7.5 and $15 \mathrm{~kg} / \mathrm{h}$ and the first $45 \mathrm{~s}$ for refill $1 \mathrm{of} 1 \mathrm{~kg} / \mathrm{h}$ trials to allow for stabilization of the feed rates and feed factors during startup of the equipment until the Instantaneous Mass Flow RSD dropped below $1 \%$. This initial startup was not representative of the entire run and continuous processes reject initial materials during startup to allow for system stabilization.

Other data that was excluded from the comparative analysis was $\mathrm{K} 4 \mathrm{M}$ CR at $15 \mathrm{~kg} / \mathrm{h}$ for time $>386 \mathrm{~s}$ which had additional refills to evaluate a long run. Also, K4M CR at $1 \mathrm{~kg} / \mathrm{h}$ for time $>3,950 \mathrm{~s}$ since it had a significantly longer run than the equivalent DC type with increasing mass flow variability after that time.

There were three events during the experiments which were excluded for cause. The first event was for the K100M DC at $7.5 \mathrm{~kg} / \mathrm{h}$ when it ran out of powder. When the situation was realized the process was stopped, more powder was added to the refill hopper and the process was run longer to complete additional refills. During this time of having an empty hopper and being topped up (484.6-706.4 sec) the data was excluded from the calculations. The second event occurred for $\mathrm{K} 100 \mathrm{M}$ DC at $15 \mathrm{~kg} / \mathrm{h}$ where the balance was disturbed when the hopper was accidently touched when checking powder levels from 122.2 to $123.6 \mathrm{~s}$. The third event was for K15M CR at $7.5 \mathrm{~kg} / \mathrm{h}$ when the door to a)

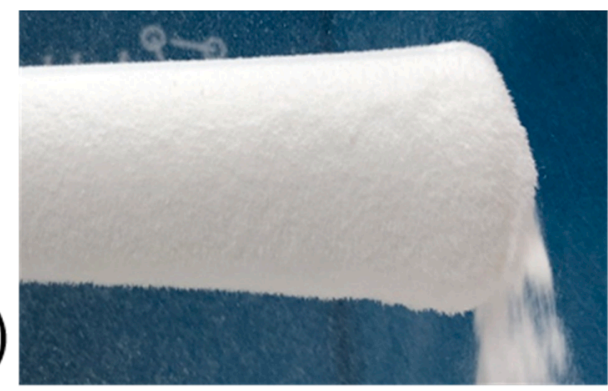

c)

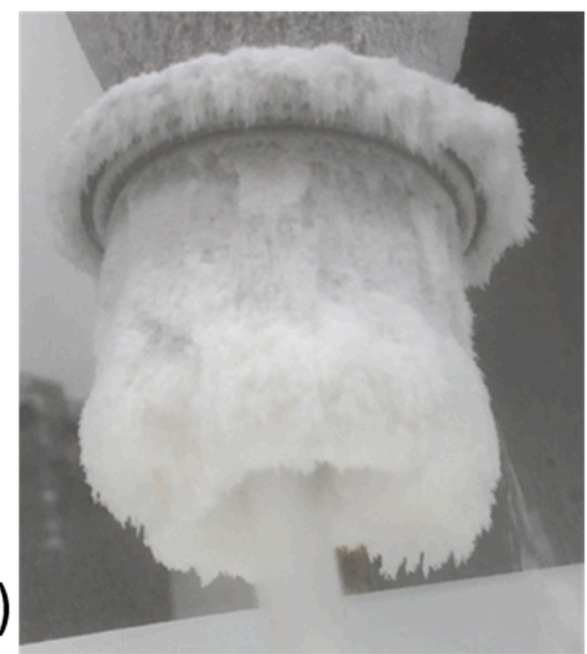

b)

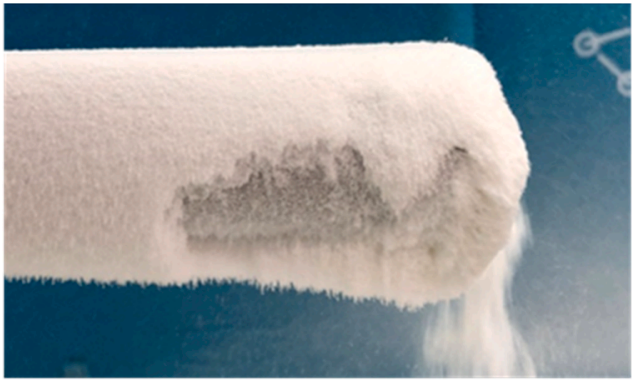

d)

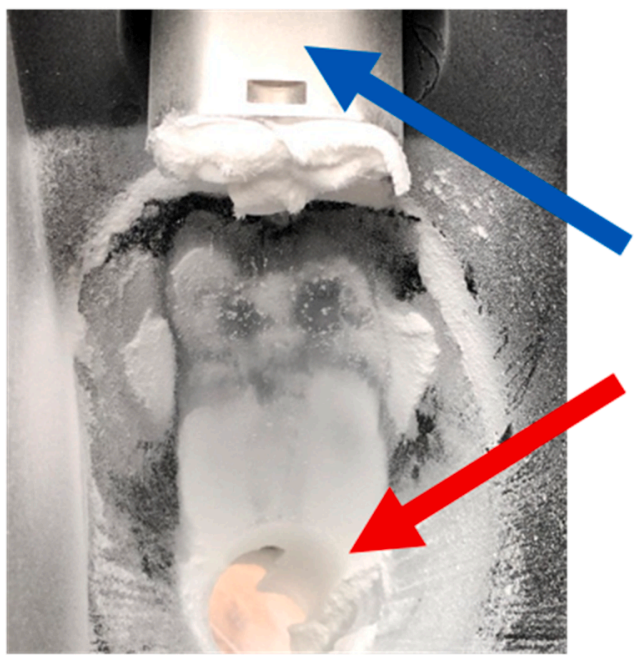

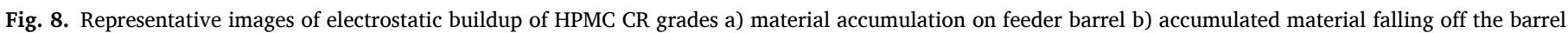

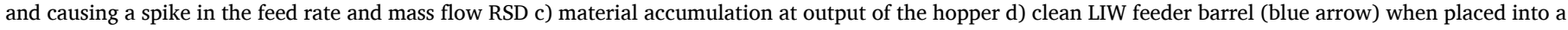
hopper with material building up at hopper output instead (red arrow). 


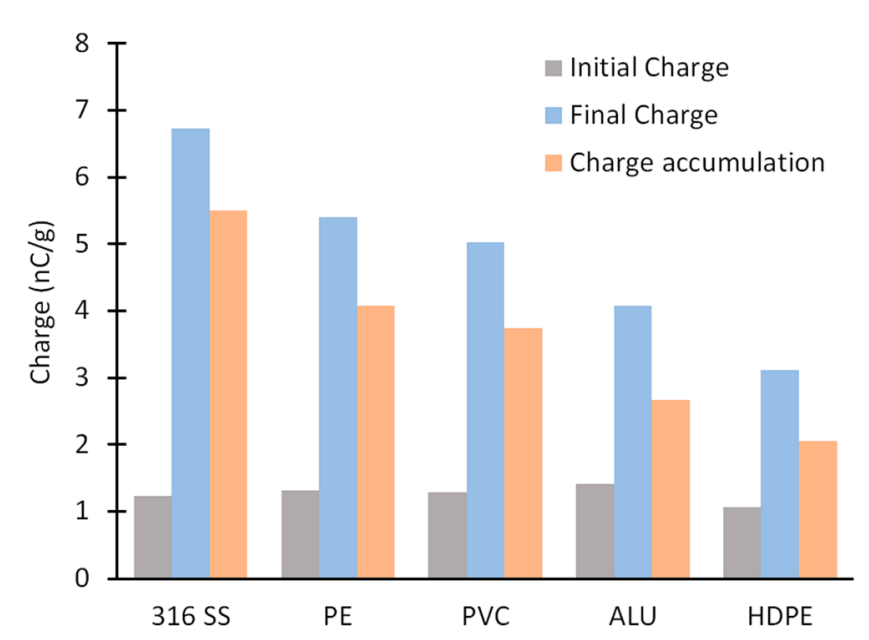

Fig. 9. Initial charge in grey, final charge in blue and charge accumulation (difference of final and initial) in orange for HPMC K100M CR measured with GranuCharge for common materials of construction using tubes of 316L Stainless Steel (316 SS), Poly-Ethylene (PE), Poly-Vinyl Chloride (PVC), Aluminum (ALU), and High Density Poly-Ethylene (HDPE).

the processing room was opened which disturbed the feeder balance between 288.0 and $290.4 \mathrm{~s}$.

The screw speed required to achieve the target mass flow rate can be dependent on the particle properties such as the bulk density, particle size, and shape. While there were slight differences in the bulk density and tapped density between the CR and DC types, it did not seem to affect the filling of the screws as the correlation between screw speed and mass flow were similar as shown in Fig. 10 with a linear increase across the ranges studied.

The LIW feeders are designed to deliver the target feed rate by using a feedback loop to automatically adjust the screw speed in response to the measured mass flow when running in gravimetric mode. The mean mass flow rates were almost identical and on target for all of the materials indicating that the LIW feeders are capable of delivering the target mass flows. The standard deviations of the mass flow rates were all low with the standard deviation and range being lower for the DC types as shown in Table 6 indicating better feeding performance.

In order to compare across feed rates, the percent difference of the measured mass flow from the target rate was calculated at each time point and demonstrated that most of the mass flow data points were

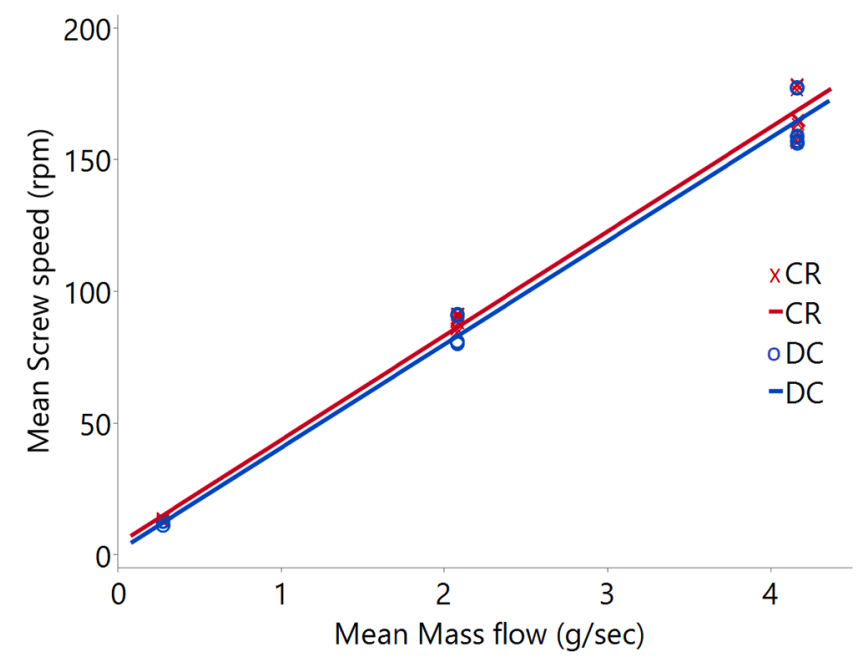

Fig. 10. Correlation between the mean screw speed and mean mass flow for each grade and rate. CR in red X and DC in blue circle. within $5 \%$ of the target rates as shown in Fig. 11. The materials were close to target with small standard deviations indicating that overall the equipment performed well for both types of material. This was expected since there is a feedback loop when running in gravimetric mode that adjusts to keep the mass flow close to target. There were occasions where the mass flows were off target at different times in the feeding trials. As shown in Fig. 11, the CR types had more excursions which were outside of $5 \%$ of the target mass flow rate compared to the DC types which were all within the $5 \%$ limit. Overall, the DC grade mean mass flow percent offset was closer to target (DC mean $=-0.0006 \%$ ) compared to the CR type (CR mean $=-0.0013 \%$ ) and the difference was statistically significant with a $\mathrm{P}$ value $<0.001$. In a multiple comparisons test for equal variances, the DC materials had lower standard deviations compared to their CR counterparts for each of the grades and the difference was also statistically significant as shown in Fig. 12.

Another measure of the acceptability of the material for use in LIW feeders is the Instantaneous Mass Flow RSD. This equipment parameter is the moving relative standard deviation of the mass flow signal using a variable window size. The window size is equal to $50 \%$ of the mass flow filter length which changed based on the flow rate, decreasing at higher speed. The Instantaneous Mass Flow RSD was similar across the feed rates with more excursions for the CR types as shown in Fig. 13. Previous studies with different feeding equipment showed that the RSD was higher for the lower feed rates (Blackshields and Crean, 2018; Li, 2015) which was not observed in this work. The mean of the Instantaneous Mass Flow RSD for all the grades combined was similar, with the DC grades being slightly lower overall as shown in Fig. 14. Across all grades and rates the mean Instantaneous Mass Flow RSD was lower for the DC materials (DC $0.334 \pm 0.246$ vs. CR $0.403 \pm 0.452$ based on over 60,000 data points each) and the difference was statistically significant with a $P$ value $<0.001$ indicating the DC materials performed better for LIW feeding.

Mass flow excursions can be caused by several factors beyond the normal variability of the process. These excursions can come from hopper refills, either just before going into a refill or coming out of a refill, external influences on the sensitive scale, and/or changes in material properties or powder flow (Hanson, 2018). Mass flow excursions can also result from material adhering to screw outlet via electrostatics as discussed in Section 3.4. As the material adheres to the screw outlet it can build up on the stainless-steel feeder barrel and occasionally excess material can fall off in varying amounts. This causes a measurable spike in the mass flow which induces a response in the feedback control slowing down the screw speed which drops the mass flow below target before eventually adjusting back to target. An example of this spike and response is shown in Fig. 13 at approximately $1250 \mathrm{~g}$ for K4M CR at 7.5 $\mathrm{kg} / \mathrm{h}$ where it was observed that a large amount of buildup fell off as shown in the pictures of Fig. 8a and 8b. A zoomed in view of the LIW feeder control system response to this spike is shown in Fig. 15.

Bridging of the powder in the feeder hopper preventing it from getting into the feeder screws is unlikely to occur in the GEA compact feeder due to the inclusion of a rotating impeller to agitate the powder. However, if the material bridges or ratholes in the feed chute leading to the refill container it can result in a failed refill attempt. There were some instances of failed refills during these trials for the CR types. Ratholes in the feed chute were observed for both K15M CR and K100M $\mathrm{CR}$ which prevented the refill from being completed. A similar phenomenon was observed in other feeder studies with different materials and equipment (Cartwright et al., 2013; Santos et al., 2018).

The number of refill attempts were evaluated to identify any challenges from the refill hopper. Even if a material has acceptable mass flow, the process overall is unacceptable if the material is not being refilled. In some instances when the refill bowl would turn to dump additional material into the hopper, the powder would not empty from the bowl or the material had bridged or formed a rathole in the feed chute preventing it from filling the refill bowl. In these cases, the lack of additional powder was recognized by the system since no mass was 
Table 6

Feeder mass flow rate, range of mass flow, and screw speed. Mean and (standard deviation) shown for mass flow and screw speed.

\begin{tabular}{|c|c|c|c|c|c|}
\hline Rate $(\mathrm{kg} / \mathrm{h})$ & Grade & Type & Mass flow $(\mathrm{g} / \mathrm{sec})$ & Range of Mass flow (g/sec) & Screw speed (rpm) \\
\hline 1 & K100M & CR & $0.278(0.003)$ & 0.024 & $13.4(0.2)$ \\
\hline 1 & K15M & CR & $0.278(0.002)$ & 0.022 & $12.4(0.2)$ \\
\hline 1 & K4M & $\mathrm{CR}$ & $0.277(0.005)$ & 0.050 & $12.6(0.2)$ \\
\hline 1 & K100M & DC & $0.278(0.002)$ & 0.017 & $11.0(0.1)$ \\
\hline 1 & K15M & DC & $0.278(0.002)$ & 0.018 & $12.4(0.2)$ \\
\hline 1 & $\mathrm{~K} 4 \mathrm{M}$ & DC & $0.278(0.002)$ & 0.019 & $11.0(0.1)$ \\
\hline 7.5 & K100M & $\mathrm{CR}$ & $2.082(0.021)$ & 0.288 & $91.1(1.2)$ \\
\hline 7.5 & K15M & CR & $2.084(0.014)$ & 0.179 & $89.7(1.5)$ \\
\hline 7.5 & K4M & CR & $2.079(0.031)$ & 0.729 & $87.3(2.4)$ \\
\hline 7.5 & K100M & DC & $2.082(0.011)$ & 0.092 & $80.5(0.8)$ \\
\hline 7.5 & K15M & DC & $2.082(0.012)$ & 0.099 & $90.9(1.0)$ \\
\hline 7.5 & K4M & DC & $2.082(0.017)$ & 0.107 & $80.8(0.9)$ \\
\hline 15 & K100M & $\mathrm{CR}$ & $4.163(0.039)$ & 0.541 & $178.0(2.0)$ \\
\hline 15 & K15M & $\mathrm{CR}$ & $4.169(0.047)$ & 1.332 & 164.5 (1.3) \\
\hline 15 & K4M & CR & $4.162(0.064)$ & 1.703 & $158.3(3.0)$ \\
\hline 15 & K100M & DC & $4.164(0.017)$ & 0.123 & $156.6(1.5)$ \\
\hline 15 & K15M & DC & $4.163(0.023)$ & 0.177 & $177.2(1.9)$ \\
\hline 15 & K4M & DC & $4.163(0.017)$ & 0.143 & 158.6 (1.9) \\
\hline
\end{tabular}

added and it would trigger another refill attempt. After the first failed refill attempt the equipment was manually tapped to help the powder fill and empty from the refill bowl. After the second failed attempt the powder above the refill bowl was stirred manually and the outside was tapped to ensure powder would be transferred to the hopper. There were two instances where the standard CR grades required two refill attempts and three instances where it took three refill attempts. The DC type did not have any failed refill attempts.

In addition to the number of refill attempts, the amount of time for the refill to occur was evaluated by determining the total amount of time spent in volumetric mode during each refill event. When the refill is occurring the LIW feeder is running in volumetric mode instead of gravimetric and the feeder mass is not being measured so there is more potential for inaccurate mass flow. After a refill occurs, the feeder stabilizes before switching back to gravimetric mode. The lowest feed rate of $1 \mathrm{~kg} / \mathrm{h}$ resulted in the longest time to refill for all materials while the 7.5 and $15 \mathrm{~kg} / \mathrm{h}$ took similar times as shown in Fig. 16. The CR type had multiple occasions where refills took longer at each of the rates resulting in longer time running in volumetric mode which increases the risk of inaccurate mass flow. For this reason, the improved flow of the DC grades is beneficial to prevent refill issues and reduce the amount of time

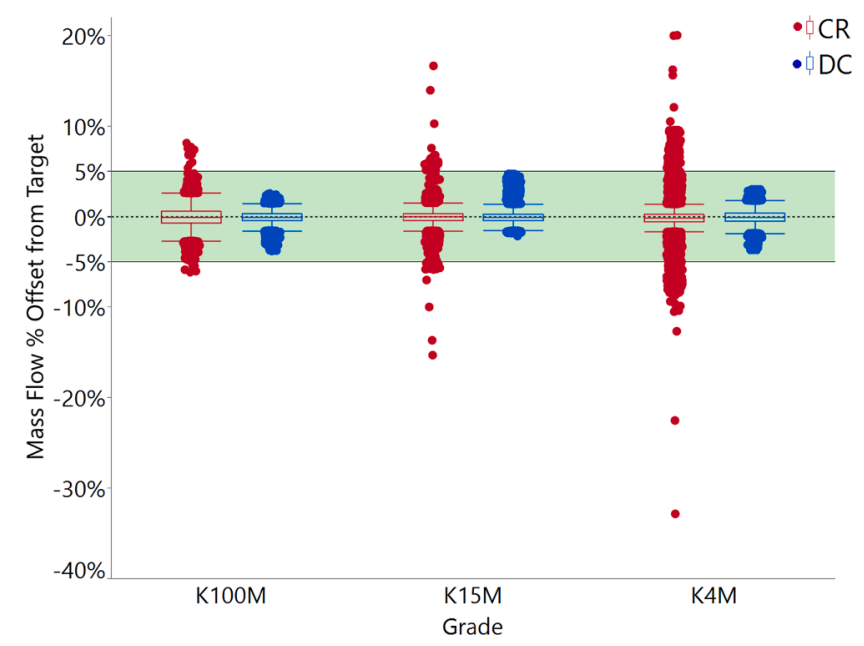

Fig. 11. Mass flow percent offset from target mass flow rate. CR in red and DC in blue. Green band indicates mass flow rate $\pm 5 \%$ from target rate. that the feeder is running in volumetric mode during refills where the actual gravimetric feed rate is not measured. The importance of refills should not be overlooked when conducting LIW feeder studies.

The K4M CR material was used to perform a longer run covering eleven refills. As can be seen in Fig. 17, the number and degree of mass flow excursions increased over time except for refills \#5 and \#8. While this was observed for the long run, there was no increase in excursions over time observed during the first three refills when comparing all the materials.

Some degree of sinusoidal variation to both the Mass Flow and the Instantaneous Mass Flow RSD was observed over a 3-5 s range for all feed rates fluctuating about $2 \%$ from the mean Mass Flow as shown in Fig. 18. A similar phenomena was also observed for silicified microcrystalline cellulose over a $2 \mathrm{~s}$ period when feeding at $12 \mathrm{~kg} / \mathrm{h}$ and measured at $0.1 \mathrm{~s}$ intervals using a different loss-in-weight feeder (Engisch and Muzzio, 2015b). The oscillations they observed were an order of magnitude larger and significantly more periodic. The authors hypothesized that it was due to free-flowing powder emptying out of each flight of the screws because when a screw with a smaller free volume was used the pulsations were reduced in magnitude. This is unlikely to be the cause for these materials as only the DC had improved flowability and the fluctuations occurred for both materials to the same

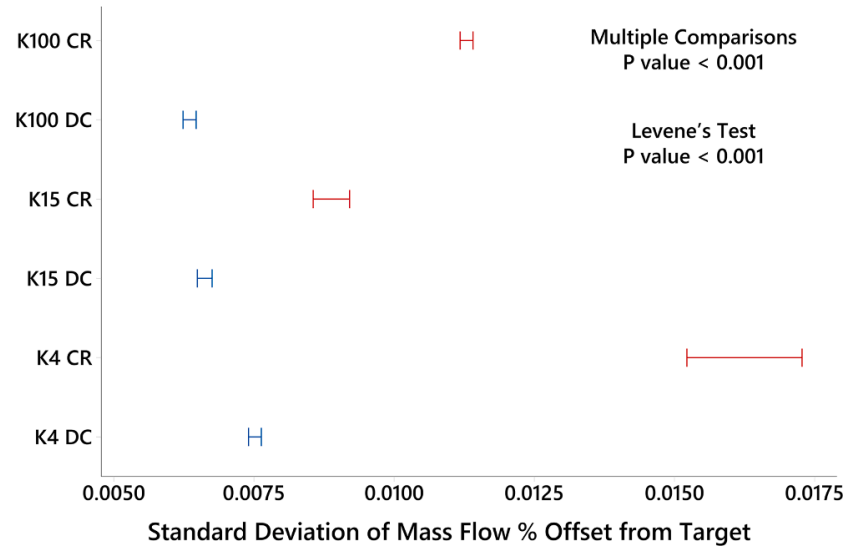

Fig. 12. Test for equal variances CR vs DC: Mass Flow Offset vs Grade Type. Multiple comparison intervals for the standard deviation, $\alpha=0.05$. If intervals do not overlap, the corresponding standard deviations are significantly different. CR in red and DC in blue. 


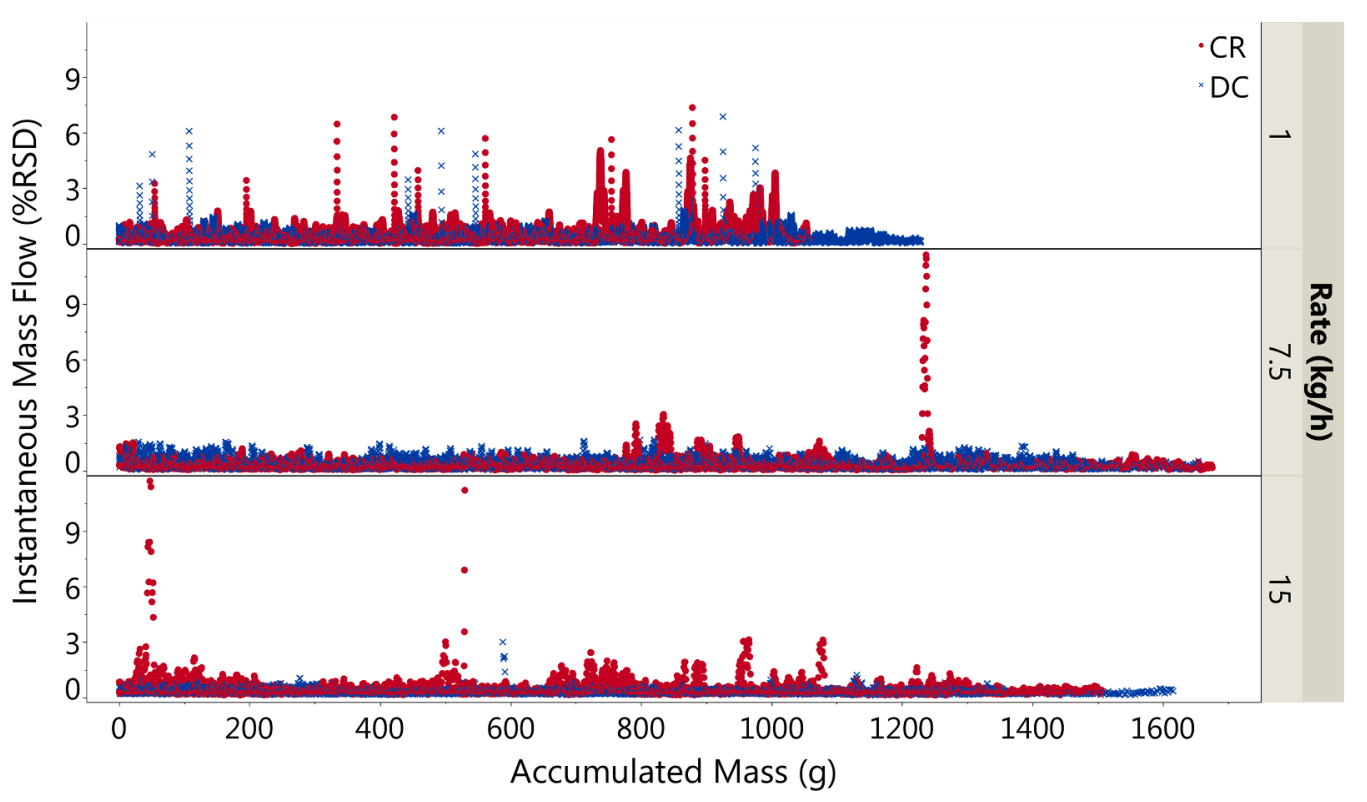

Fig. 13. Instantaneous mass flow RSD by the total accumulated mass of the material fed including refills for each of the feed rates. CR in red and DC in blue. Refill events not shown.

extent.

\section{Conclusions}

The bulk density and tapped density were higher for the DC HPMC types. It was expected that this difference in density would affect the packing of the material in the screw and result in lower screw speeds required to achieve the target mass flow, but this was not the case. Both CR and DC had similar screw speeds with a linear increase in the screw speed / mass flow relationship over the range studied.

It was demonstrated previously via different powder flow testing methodologies that the directly compressible (DC) HPMC had better flow properties compared to the standard (CR) HPMC even though they had similar particle size and morphology (Allenspach et al., 2020). This work also demonstrated improved flow overall for the DC HPMC with additional testing methodologies. The angle of repose, heap height, flow angle and cohesive index all indicated that the DC types had better flow while the cohesion index from the angle of repose and the Hausner ratio from bulk and tapped density did not show differences in the materials.

Even though the DC material showed better flow, it was not known if that would translate into improved LIW feeding since the equipment utilizes a feedback loop to keep the feed rate at target. While the mass flow was kept on target for all materials, the DC HPMC had lower mass flow standard deviations, smaller ranges for the mass flow, less excursions and lower standard deviations of the mass flow offset from target. These results were observed across all three HPMC grades and all three feed rates leading to the conclusion that the DC HPMC performed better for LIW feeding across the ranges studied. Depending on the system and sensitivity, it is possible that the excursions in the CR HPMC would be blended out during downstream processing in the continuous manufacturing train. However, the impact of variability is both process and formulation dependent, and would require an understanding of residence time distributions for the entire system to determine how frequently and to what degree these mass flow deviations would be acceptable.

Another important aspect to LIW feeding is the refill to the hopper. Even if the system can handle the larger variability and excursions with the CR HPMC the materials need to be refilled frequently as the feeder hopper runs out of material. If the material bridges or creates a rathole it can be very problematic for a process which is meant to run continuously. The DC HPMC all refilled the LIW feeder hopper on the first attempt, but the CR HPMC had instances where the hopper refill failed. On multiple occasions for CR HPMC, the equipment needed to be stopped after a failed refill to manually intervene. This performance would be extremely problematic for a continuous manufacturing system which is designed to be run constantly without interruption and where accessing the powders would be very challenging because of the sealed and contained nature of the equipment. It was also detrimental to the mass flow because the equipment switches to volumetric dosing during a refill. At this stage the actual mass flow is not being measured since more powder is being added to the balance. During this time, the system is prone to feeding inaccuracies which are not being measured. In some cases, when there was a failed refill, it resulted in volumetric dosing which lasted four times longer.

The importance of fully characterizing the powders intended to be used in a LIW feeder was demonstrated by the triboelectric charging of the materials. DC HPMC had significantly lower triboelectric charging compared to the CR type. The initial charge, final charge and charge accumulation were closer to zero for the DC HPMC. The criticality of this

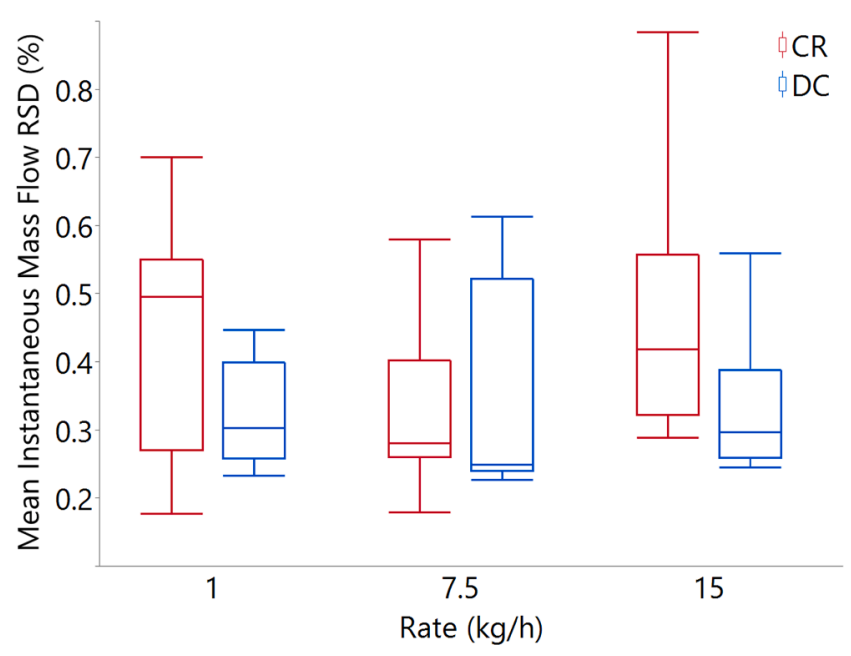

Fig. 14. Mean instantaneous mass flow RSD by feed rate for all materials per refill. CR in red and DC in blue. 


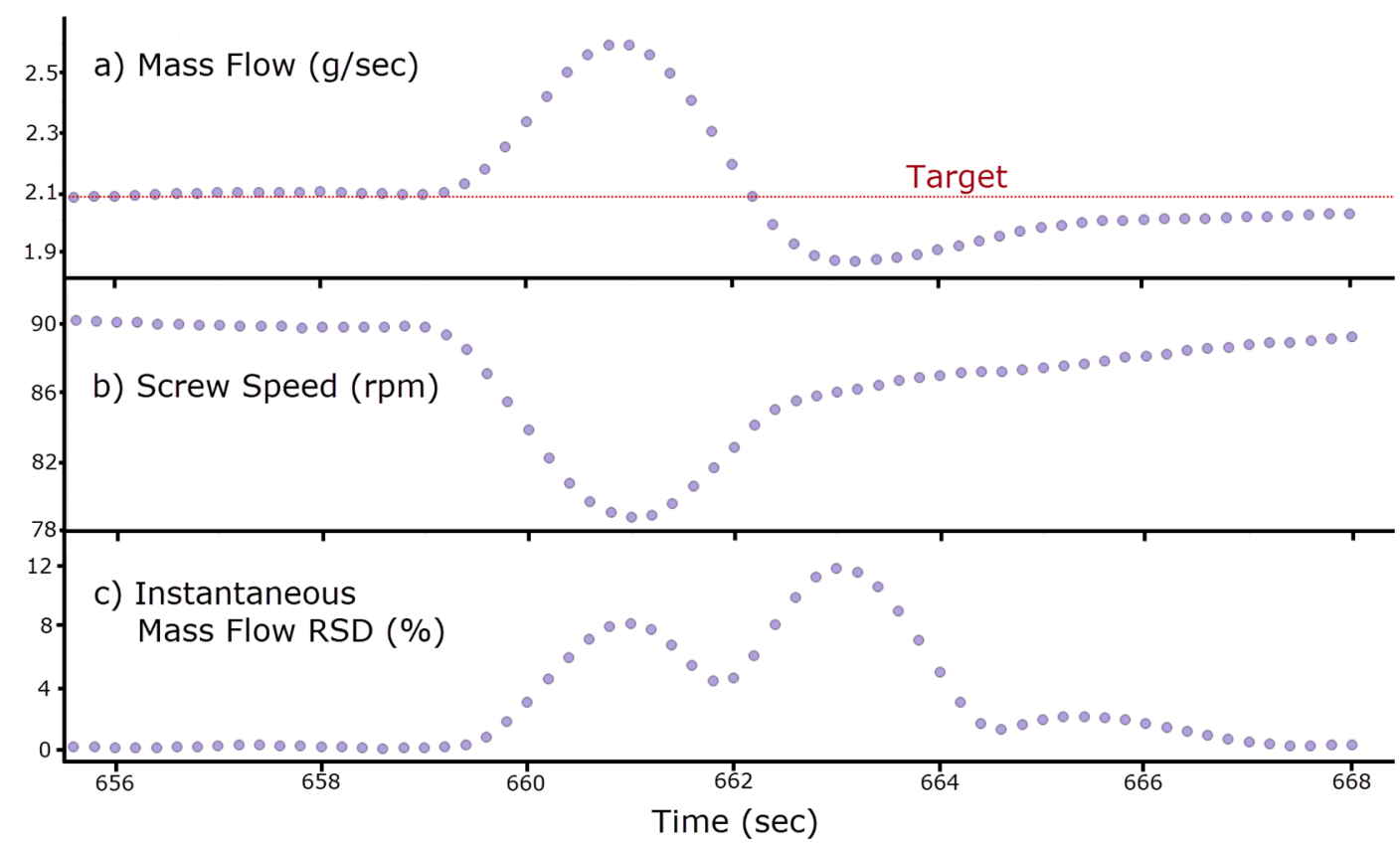

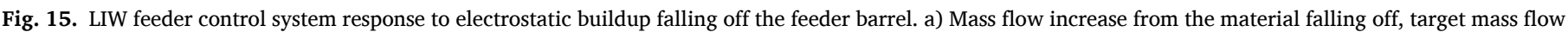

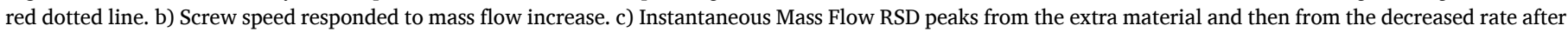
the screw speed responded to the extra material.

was observed in the feeding trials where the CR types had high amounts of electrostatic buildup of material on the feeder barrel and resulted in increased number of mass flow excursions during the run. Even more critical was the observation that the location of the electrostatic buildup of material changed when the feeders were placed into the continuous system. This effectively 'blinds' the control system so that any buildup and subsequent spikes from material falling off are no longer observed by the sensors. When the material was tested using offline feeders the buildup was on the feeder barrel which is connected to the mass sensors. When the feeders were connected to the hopper the buildup occurred at the outlet of the hopper instead. In this way, the results from feeding studies using an offline LIW feeder going into a container may not be transferrable to a full, contained continuous manufacturing system when there are electrostatic effects in play as well as other materials which could either mitigate or increase the effect. Most continuous manufacturing systems are sealed and contained which could help to prevent electrostatic material buildup but would also make it extremely difficult to observe or detect if it did occur elsewhere inside the system.

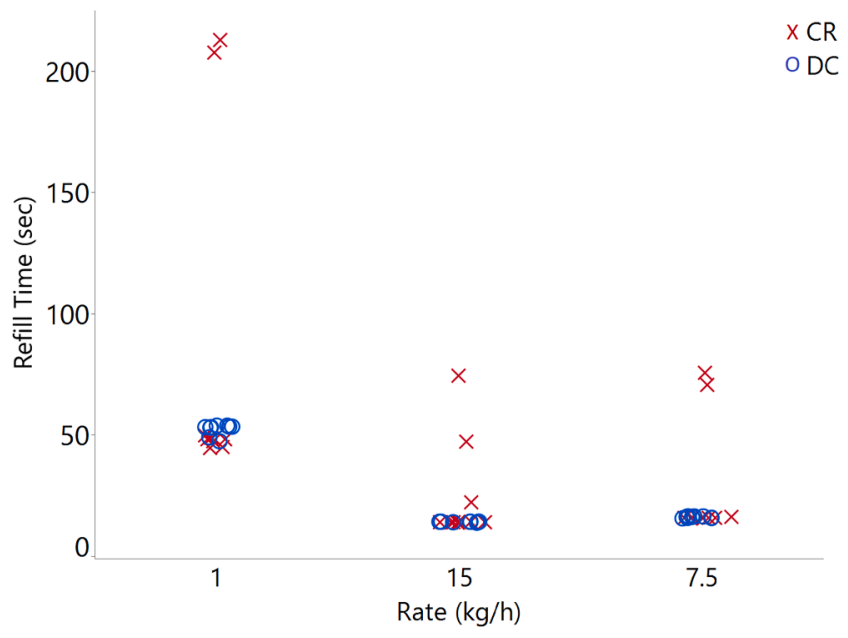

Fig. 16. Time for a refill of the hopper to occur. CR red X and DC blue circle.
The direct compression (DC) grades of HPMC were developed for better flowability and improved tablet compactability but these improvements also apply to LIW feeding providing for tighter control over the mass flow, reduced triboelectric charging, fewer feed rate excursions, and more consistent refills. Avoiding the complications of acquiring a rathole in the powder inside the system is a significant advantage by itself, even if the higher feed variability and excursions

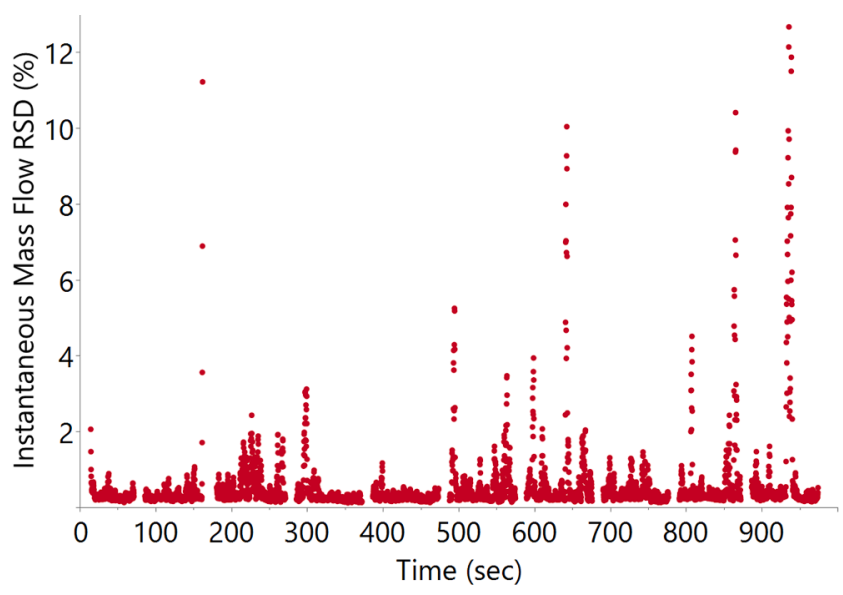

Fig. 17. Instantaneous mass flow RSD for long run of K4M CR over time. Breaks in data indicate a refill event.

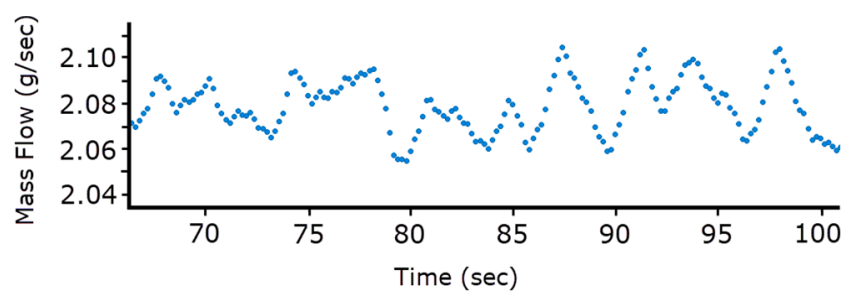

Fig. 18. Example of periodic fluctuations in mass flow over a short time frame for $\mathrm{K} 100 \mathrm{M}$ CR at $7.5 \mathrm{~kg} / \mathrm{h}$. 
with CR HPMC were acceptable for the system. All of these improvements observed with DC HPMC would be beneficial when running any continuous process (wet granulation, roller compaction, or direct compression) or other processes where LIW feeding could be utilized such as melt extrusion or twin-screw granulation.

\section{CRediT authorship contribution statement}

Carl Allenspach: Methodology, Resources, Investigation, Data curation, Formal analysis, Visualization, Writing - original draft. Peter Timmins: Conceptualization, Writing - review \& editing. Geoffroy Lumay: Writing - review \& editing. James Holman: Writing - review \& editing. Tamara Minko: Supervision, Writing - review \& editing.

\section{Declaration of Competing Interest}

The authors declare that they have no known competing financial interests or personal relationships that could have appeared to influence the work reported in this paper.

\section{Acknowledgements}

All materials were provided by Ashland with special thanks to Thomas Durig and Susan McHugh for their help as well as Brian Phillips and Daniel Sieber for their input. The authors would like to thank GranuTools for the use of the powder characterization equipment. The authors would like to thank GEA for the use of the LIW compact feeder and Andrew Birkmire, Jessica Zombek, Erica Anderson and Tyron Lunn for their support with the LIW feeder trials. This research did not receive any specific grant from funding agencies in the public, commercial, or not-for-profit sectors.

\section{References}

Allenspach, C., Timmins, P., Sharif, S., Minko, T., 2020. Characterization of a novel hydroxypropyl methylcellulose (HPMC) direct compression grade excipient for pharmaceutical tablets. Int. J. Pharm. 119343.

Andreou, J., Stewart, P., Morton, D., 2009. Short-term changes in drug agglomeration within interactive mixtures following blending. Int. J. Pharm. 372, 1-11.

Bailey, A., 1984. Electrostatic phenomena during powder handling. Powder Technol. 37, $71-85$.

Beakawi Al-Hashemi, H.M., Baghabra Al-Amoudi, O.S., 2018. A review on the angle of repose of granular materials. Powder Technol. 330, 397-417.

Beeckmans, J., Inculet, I., Dumas, G., 1979. Enhancement in segregation of a mixed powder in a fluidized bed in the presence of an electrostatic field. Powder Technol. 24, 267-269.

Berthiaux, H., Marikh, K., Gatumel, C., 2008. Continuous mixing of powder mixtures with pharmaceutical process constraints. Chem. Eng. Process. Process Intensif. 47, 2315-2322.

Bhaskar, A., Singh, R., 2019. Residence time distribution (RTD)-based control system for continuous pharmaceutical manufacturing process. J. Pharmaceut. Innov. 14, 316-331.

Blackshields, C.A., Crean, A.M., 2018. Continuous powder feeding for pharmaceutical solid dosage form manufacture: a short review. Pharm. Dev. Technol. 23, 554-560.

Boschini, F., Delaval, V., Traina, K., Vandewalle, N., Lumay, G., 2015. Linking flowability and granulometry of lactose powders. Int. J. Pharm. 494, 312-320.

Carter, P.A., Rowley, G., Fletcher, E.J., Stylianopoulos, V., 1998. Measurement of electrostatic charge decay in pharmaceutical powders and polymer materials used in dry powder inhaler devices. Drug Dev. Ind. Pharm. 24, 1083-1088.

Cartwright, J.J., Robertson, J., D'Haene, D., Burke, M.D., Hennenkamp, J.R., 2013. Twin screw wet granulation: Loss in weight feeding of a poorly flowing active pharmaceutical ingredient. Powder Technol. 238, 116-121.

Ceresiat, L., Grosshans, H., Papalexandris, M.V., 2019. Powder electrification during pneumatic transport: The role of the particle properties and flow rates. J. Loss Prev. Process Ind. 58, 60-69.

Chatterjee, S., 2012. FDA Perspective on Continuous Manufacturing. IFPAC Annual Meeting, Baltimore, MD, pp. 34-42.

The Dow Chemical Company, 2006. Using Dow Excipients for Controlled Release of Drugs in Hydrophilic Matrix Systems. The Dow Chemical Company, U.S.A., p. 36.

DesRosiers Lachiver, E., Abatzoglou, N., Cartilier, L., Simard, J.-S., 2006. Insights into the role of electrostatic forces on the behavior of dry pharmaceutical particulate systems. Pharm. Res. 23, 997-1007.

Engisch, W.E., Muzzio, F.J., 2012. Method for characterization of loss-in-weight feeder equipment. Powder Technol. 228, 395-403.

Engisch, W.E., Muzzio, F.J., 2015a. Feedrate deviations caused by hopper refill of loss-inweight feeders. Powder Technol. 283, 389-400.
Engisch, W.E., Muzzio, F.J., 2015b. Loss-in-weight feeding trials case study: pharmaceutical formulation. J. Pharmaceut. Innov 10, 56-75.

Escotet Espinoza, M., 2018. Phenomenological and Residence Time Distribution Models for Unit Operations in a Continuous Pharmaceutical Manufacturing Process. Rutgers University-School of Graduate Studies.

Gao, Y., Vanarase, A., Muzzio, F., Ierapetritou, M., 2011. Characterizing continuous powder mixing using residence time distribution. Chem. Eng. Sci. 66, 417-425.

Ghori, M., Šupuk, E., Conway, B., 2015. Tribo-electrification and powder adhesion studies in the development of polymeric hydrophilic drug matrices. Materials 8 , 1482-1498.

Ghori, M.U., Šupuk, E., Conway, B.R., 2014. Tribo-electric charging and adhesion of cellulose ethers and their mixtures with flurbiprofen. Eur. J. Pharm. Sci. 65, 1-8.

Gohel, M., Jogani, P.D., 2005. A review of co-processed directly compressible excipients. J. Pharm. Pharm. Sci. 8, 76-93.

Grey, R., Beddow, J., 1969. On the Hausner ratio and its relationship to some properties of metal powders. Powder Technol. 2, 323-326.

Hanson, J., 2018. Control of a system of loss-in-weight feeders for drug product continuous manufacturing. Powder Technol. 331, 236-243.

Hao, T., Tukianen, J., Nivorozhkin, A., Landrau, N., 2013. Probing pharmaceutical powder blending uniformity with electrostatic charge measurements. Powder Technol. 245, 64-69.

Harwood, C.F., Walanski, K., Luebcke, E., Swanstrom, C., 1975. The performance of continuous mixers for dry powders. Powder Technol. 11, 289-296.

Ierapetritou, M., Muzzio, F., Reklaitis, G., 2016. Perspectives on the continuous manufacturing of powder-based pharmaceutical processes. AIChE J. 62, 1846-1862.

Ireland, P.M., 2010a. Triboelectrification of particulate flows on surfaces: Part I-Experiments. Powder Technol. 198, 189-198.

Ireland, P.M., 2010b. Triboelectrification of particulate flows on surfaces: Part II-Mechanisms and models. Powder Technol. 198, 199-210.

Kaialy, W., 2016. A review of factors affecting electrostatic charging of pharmaceuticals and adhesive mixtures for inhalation. Int. J. Pharm. 503, 262-276.

Karttunen, A.-P., Hörmann, T.R., De Leersnyder, F., Ketolainen, J., De Beer, T., Hsiao, W.K., Korhonen, O., 2019. Measurement of residence time distributions and material tracking on three continuous manufacturing lines. Int. J. Pharm. 563, 184-197.

Leane, M., Pitt, K., Reynolds, G., Group, M.C.S.W., 2015. A proposal for a drug product Manufacturing Classification System (MCS) for oral solid dosage forms. Pharmaceutical development and technology 20, 12-21.

Li, P., 2015. Effect of Powder Flow Properties on the Process Performance of Loss-inweight Feeders. The State University of New Jersey-New, Brunswick.

Lumay, G., Boschini, F., Traina, K., Bontempi, S., Remy, J.-C., Cloots, R., Vandewalle, N., 2012. Measuring the flowing properties of powders and grains. Powder Technol. 224, 19-27.

Lumay, G., Pillitteri, S., Marck, M., Monsuur, F., Pauly, T., Ribeyre, Q., Francqui, F., Vandewalle, N., 2019. Influence of mesoporous silica on powder flow and electrostatic properties on short and long term. J. Drug Delivery Sci. Technol. 53, 101192.

Mäki, R., Suihko, E., Rost, S., Heiskanen, M., Murtomaa, M., Lehto, V.P., Ketolainen, J., 2007. Modifying drug release and tablet properties of starch acetate tablets by dry powder agglomeration. J. Pharm. Sci. 96, 438-447.

Matsusaka, S., Maruyama, H., Matsuyama, T., Ghadiri, M., 2010. Triboelectric charging of powders: A review. Chem. Eng. Sci. 65, 5781-5807.

Mukherjee, R., Gupta, V., Naik, S., Sarkar, S., Sharma, V., Peri, P., Chaudhuri, B., 2016. Effects of particle size on the triboelectrification phenomenon in pharmaceutical excipients: Experiments and multi-scale modeling. Asian J. Pharmaceut. Sci. 11, 603-617.

Nachaegari, S.K., Bansal, A.K., 2004. Coprocessed excipients for solid dosage forms. Pharm. Technol. 28, 52-65.

Naik, S., Hancock, B., Abramov, Y., Yu, W., Rowland, M., Huang, Z., Chaudhuri, B., 2016a. Quantification of tribocharging of pharmaceutical powders in V-blenders: experiments, multiscale modeling, and simulations. J. Pharm. Sci. 105, 1467-1477.

Naik, S., Mukherjee, R., Chaudhuri, B., 2016b. Triboelectrification: A review of experimental and mechanistic modeling approaches with a special focus on pharmaceutical powders. Int. J. Pharm. 510, 375-385.

Naik, S., Sarkar, S., Gupta, V., Hancock, B.C., Abramov, Y., Yu, W., Chaudhuri, B., 2015. A combined experimental and numerical approach to explore tribocharging of pharmaceutical excipients in a hopper chute assembly. Int. J. Pharm. 491, 58-68.

Naik, S., Sarkar, S., Hancock, B., Rowland, M., Abramov, Y., Yu, W., Chaudhuri, B., 2016c. An experimental and numerical modeling study of tribocharging in pharmaceutical granular mixtures. Powder Technol. 297, 211-219.

Nwose, E.N., Pei, C., Wu, C.-Y., 2012. Modelling die filling with charged particles using DEM/CFD. Particuology 10, 229-235.

O'Connor, T., 2019. FDA perspective on continuous manufacturing Journey: Past, Present, and Future, AAPS PharmSci 360, San Antonio, TX.

Palmer, J., Reynolds, G.K., Tahir, F., Yadav, I.K., Meehan, E., Holman, J., Bajwa, G. 2020. Mapping key process parameters to the performance of a continuous dry powder blender in a continuous direct compression system. Powder Technol. 362, $659-670$.

Peart, J., 2001. Powder electrostatics: theory, techniques and applications. Kona Powder Part. J. 19, 34-45.

Pernenkil, L., Cooney, C.L., 2006. A review on the continuous blending of powders. Chem. Eng. Sci. 61, 720-742.

Pharmacopeia, U.S., 2018. Powder Flow, Issue 44 Number 6. The U.S. Pharmacopeial Convention.

Pingali, K.C., Chatarla, S.K., Tracy, B.A., Byrnes, B.A., 2016. Sensing electrostatic charge generation during granular flow of pharmaceutical powders in a flow tester. J. Pharmaceut. Innov. 11, 179-188. 
Pu, Y., Mazumder, M., Cooney, C., 2009. Effects of electrostatic charging on pharmaceutical powder blending homogeneity. J. Pharm. Sci. 98, 2412-2421.

Qiu, Y., Chen, Y., Zhang, G.G., Yu, L., Mantri, R.V., 2016. Developing Solid Oral Dosage Forms: Pharmaceutical Theory and Practice. Academic Press.

Ramirez-Dorronsoro, J.-C., Jacko, R.B., Kildsig, D.O., 2006. Chargeability measurements of selected pharmaceutical dry powders to assess their electrostatic charge control capabilities. AAPS PharmSciTech 7, E133-E140.

Rescaglio, A., De Smet, F., Aerts, L., Lumay, G., 2019. Tribo-electrification of pharmaceutical powder blends. Part. Sci. Technol. 1-8.

Rojas, J., Buckner, I., Kumar, V., 2012. Co-proccessed excipients with enhanced direct compression functionality for improved tableting performance. Drug Dev. Ind. Pharm. 38, 1159-1170.

Saha, S., Shahiwala, A.F., 2009. Multifunctional coprocessed excipients for improved tabletting performance. Expert Opin. Drug Deliv. 6, 197-208.

Samiei, L., Kelly, K., Taylor, L., Forbes, B., Collins, E., Rowland, M., 2017. The influence of electrostatic properties on the punch sticking propensity of pharmaceutical blends. Powder Technol. 305, 509-517.

Santos, B., Carmo, F., Schlindwein, W., Muirhead, G., Rodrigues, C., Cabral, L., Westrup, J., Pitt, K., 2018. Pharmaceutical excipients properties and screw feeder performance in continuous processing lines: a Quality by Design (QbD) approach. Drug Dev. Ind. Pharm. 44, 2089-2097.

Schaber, S.D., Gerogiorgis, D.I., Ramachandran, R., Evans, J.M., Barton, P.I., Trout, B.L., 2011. Economic analysis of integrated continuous and batch pharmaceutical manufacturing: a case study. Ind. Eng. Chem. Res. 50, 10083-10092.

Schella, A., Herminghaus, S., Schröter, M., 2017. Influence of humidity on tribo-electric charging and segregation in shaken granular media. Soft Matter 13, 394-401.

Simonaho, S.-P., Ketolainen, J., Ervasti, T., Toiviainen, M., Korhonen, O., 2016. Continuous manufacturing of tablets with PROMIS-line-Introduction and case studies from continuous feeding, blending and tableting. Eur. J. Pharm. Sci. 90, 38-46.

Staniforth, J., Rees, J., 1982. Electrostatic charge interactions in ordered powder mixes. J. Pharm. Pharmacol. 34, 69-76.

Staniforth, J., Rees, J.E., 1981. Powder mixing by triboelectrification. Powder Technol. 30, 255-256.

Šupuk, E., Zarrebini, A., Reddy, J.P., Hughes, H., Leane, M.M., Tobyn, M.J., Timmins, P., Ghadiri, M., 2012. Tribo-electrification of active pharmaceutical ingredients and excipients. Powder Technol. 217, 427-434.
Tewari, D., Titova, Y.A., Beissner, B., Durig, T., 2019. Coprocessed silica coated polymer composition. ISP Investments LLC, Hercules LLC.

Timmins, P., Allenspach, C., 2018. Particle Properties: Impact on the Processing and Performance of Oral Extended-Release Hydrophilic Matrix Tablets, Particles and Nanoparticles in Pharmaceutical Products. Springer, pp. 347-372.

Timmins, P., Pygall, S.R., Melia, C.D., 2014. Hydrophilic Matrix Tablets for Oral Controlled Release. Springer.

Tomar, M., Sinha, A.R., Singh, A.K., 2017. Process and development of co-processed excipient silicified microcrystalline cellulose and manufacture paracetamol tablet by direct compression. Int. J. Pharm. Sci. Rev. Res 42, 191-196.

Van Snick, B., Holman, J., Cunningham, C., Kumar, A., Vercruysse, J., De Beer, T., Remon, J.P., Vervaet, C., 2017a. Continuous direct compression as manufacturing platform for sustained release tablets. Int. J. Pharm. 519, 390-407.

Van Snick, B., Holman, J., Vanhoorne, V., Kumar, A., De Beer, T., Remon, J., Vervaet, C., 2017b. Development of a continuous direct compression platform for low-dose drug products. Int. J. Pharm. 529, 329-346.

Van Snick, B., Kumar, A., Verstraeten, M., Pandelaere, K., Dhondt, J., Di Pretoro, G., De Beer, T., Vervaet, C., Vanhoorne, V., 2019. Impact of material properties and process variables on the residence time distribution in twin screw feeding equipment. Int. J. Pharm. 556, 200-216.

Vanarase, A.U., Osorio, J.G., Muzzio, F.J., 2013. Effects of powder flow properties and shear environment on the performance of continuous mixing of pharmaceutical powders. Powder Technol. 246, 63-72.

Wang, S., Li, J., Lin, X., Feng, Y., Kou, X., Babu, S., Panicucci, R., 2015. Novel coprocessed excipients composed of lactose, HPMC, and PVPP for tableting and its application. Int. J. Pharm. 486, 370-379.

Watanabe, H., Ghadiri, M., Matsuyama, T., Ding, Y.L., Pitt, K.G., Maruyama, H., Matsusaka, S., Masuda, H., 2007. Triboelectrification of pharmaceutical powders by particle impact. Int. J. Pharm. 334, 149-155.

Weinekötter, R., Reh, L., 1995. Continuous mixing of fine particles. Part. Part. Syst. Char. $12,46-53$.

Williams, J., 1976. Continuous mixing of solids. A review. Powder Technol. 15, 237-243.

Wong, J., Kwok, P.C.L., Chan, H.-K., 2015. Electrostatics in pharmaceutical solids. Chem. Eng. Sci. 125, 225-237. 